\title{
La decoración arquitectónica del campamento de la legio VII gemina en León'
}

\author{
Ángel MORILLO (Universidad Complutense) \\ Javier SALIDO DOMÍNGUEZ (Escuela de Historia y Arqueología en Roma-CSIC)
}

\begin{abstract}
Resumen
A partir de los hallazgos de elementos de decoración arquitectónica recuperados en la ciudad de León a lo largo de los últimos años, que constituyen un conjunto modesto pero bastante representativo, se traza un panorama sobre los programas arquitectónicos y ornamentales del antiguo campamento de la legio VII gemina en León, analizándolos desde el punto de vista arqueológico y topográfico. Lejos de la imagen de sencillez y simplicidad constructiva que parecen caracterizar a los acantonamientos militares, las columnas, frisos decorativos y revestimientos marmóreos recuperados confirman la existencia de edificios monumentales, algunos de ellos profusamente decorados (termas, cuartel general). Dicha monumentalidad se convierte en una expresión más del poder imperial, en este caso expresado a través de la arquitectura militar de uno de los principales asentamientos del ejército romano en Hispania durante el periodo altoimperial.
\end{abstract}

Palabras clave: Arqueología; decoración arquitectónica; mármoles; campamentos romanos; León.

\section{Summary}

The study of the fragments of ornamental stones found in the archaeological interventions developed in León, allows us to draw some conclusions about the architectural ornament in the camp of the legio VII gemina, paying the special attention to the archaeological and topographical context of the finds. While we may assume that the Roman camps have a rather impoverished monumental appearance, a closer investigation on the singles findspots of columns, wall piers, friezes and marble cladding confirm the existence of monumental buildings, some of them highly-decorated (baths, headquarters). This becomes a monumental expression of imperial power, expressed through the military architecture of one of the main settlements of the Roman army in Hispania during the Principate.

Keywords: Archeology; architectural decoration; marble; Roman camps; León.

Las intervenciones arqueológicas desarrolladas a lo largo de los últimos veinte años en diferentes lugares del casco histórico de la ciudad de León, en el área ocupada por los sucesivos campamentos romanos que aquí se asentaron, proporcionan un escaso pero interesante conjunto de ele- mentos de decoración arquitectónica, realizados tanto en materiales nobles como en piedras locales $^{2}$. Junto con basas, fustes y un único capitel, se han puesto al descubierto, en el sector de Puerta Obispo, cornisas y placas de revestimiento, en su mayoría de mármol, además de un gran labrum
1 El presente trabajo se ha elaborado en el marco del Proyecto de I+D HAR2011-24095: Campamentos y territorios militares de Hispania, así como del convenio de investigación: Los campamentos romanos de las legiones VI victrix y VII gemina en León. Estudio del material arqueológico procedentes de las excavaciones arqueólogicas en la ciudad de León (Casa Pallares y Santa Marina), en el marco del Plan PAHIS 2004-2012 del Patrimonio Histórico de Castilla y León, ambos bajo la dirección de A. Morillo.
2 Agradecemos a V. García Marcos, Arqueólogo Municipal de León y director de varias intervenciones arqueológicas cuyos materiales se mencionan en este trabajo, la ayuda prestada. Asimismo queremos agradecer también las facilidades y amabilidad para el acceso al material depositado en el mismo al personal del Museo de León, en particular a Miryam Hernández y a Manuel García Garrido. Deseamos dar las gracias también a Isabel Roda (ICAC) y a Miguel Cisneros por la lectura previa del original y sus opiniones y sugerencias. 
perteneciente al mobiliario decorativo de un gran edificio público, dado a conocer recientemente (Morillo \& Salido, 2010). Todos ellos se encuentran vinculados al campamento de la legio VII gemina, unidad que se establece en este lugar a comienzos del periodo flavio sobre los antiguos castra de la legio VI victrix, permaneciendo hasta un momento indeterminado del siglo IV d. C.

El análisis de los materiales exhumados que aquí presentamos proporciona interesantes consideraciones sobre el sistema constructivo, la cronología, reformas y momento de abandono de determinados edificios, el programa decorativo del que formaron parte, además de plantear la cuestión de las canteras y el aprovisionamiento de materiales marmóreos, así como los posibles talleres lapidarios.

A continuación presentamos el catálogo de elementos decorativos, organizado por lugares de hallazgo y, en su caso, tipo de material.

\section{SECTOR PUERTA OBISPO}

Las excavaciones desarrolladas durante el año 1996 en el sector de Puerta Obispo, situado al este de la ciudad, donde se ubicaba de la antigua porta principalis sinistra del campamento romano y a escasa distancia de las antiguas grandes termas legionarias, proporcionaron uno de los conjuntos más numerosos de elementos de decoración arquitectónica documentados hasta el momento en la ciudad de León. El lugar de procedencia de la mayor parte de dichos materiales debe ser el vecino establecimiento termal romano.

\section{BASAS}

1.- $\mathrm{N}^{\circ}$ inv.: 2004/20/4068/A; subsector Termas/Muralla; UE 4068.

Dimensiones: Alt. 17-22 cm.; Diám.: 26 cm.; Alt. plinto: 5-10 cm; Diám. toro: $24,5 \mathrm{~cm}$; Diám. imoscapo: $18 \mathrm{~cm}$.

Basa toscana de columna con gran plinto fracturado en la parte superior (Fig. 1). Separado por un listel se dispone un toro de perfil en arco de circunferencia de gran abertura, seguido de un caveto que enlaza con el imoscapo.

La basa está tallada en piedra caliza. Presenta numerosas inscripciones medievales en tres de las caras del plinto, así como en el listel que separa éste del toro. La posición de las letras nos indica claramente que la basa romana fue reutilizada como capitel en época medieval, posiblemente adosado a un muro.

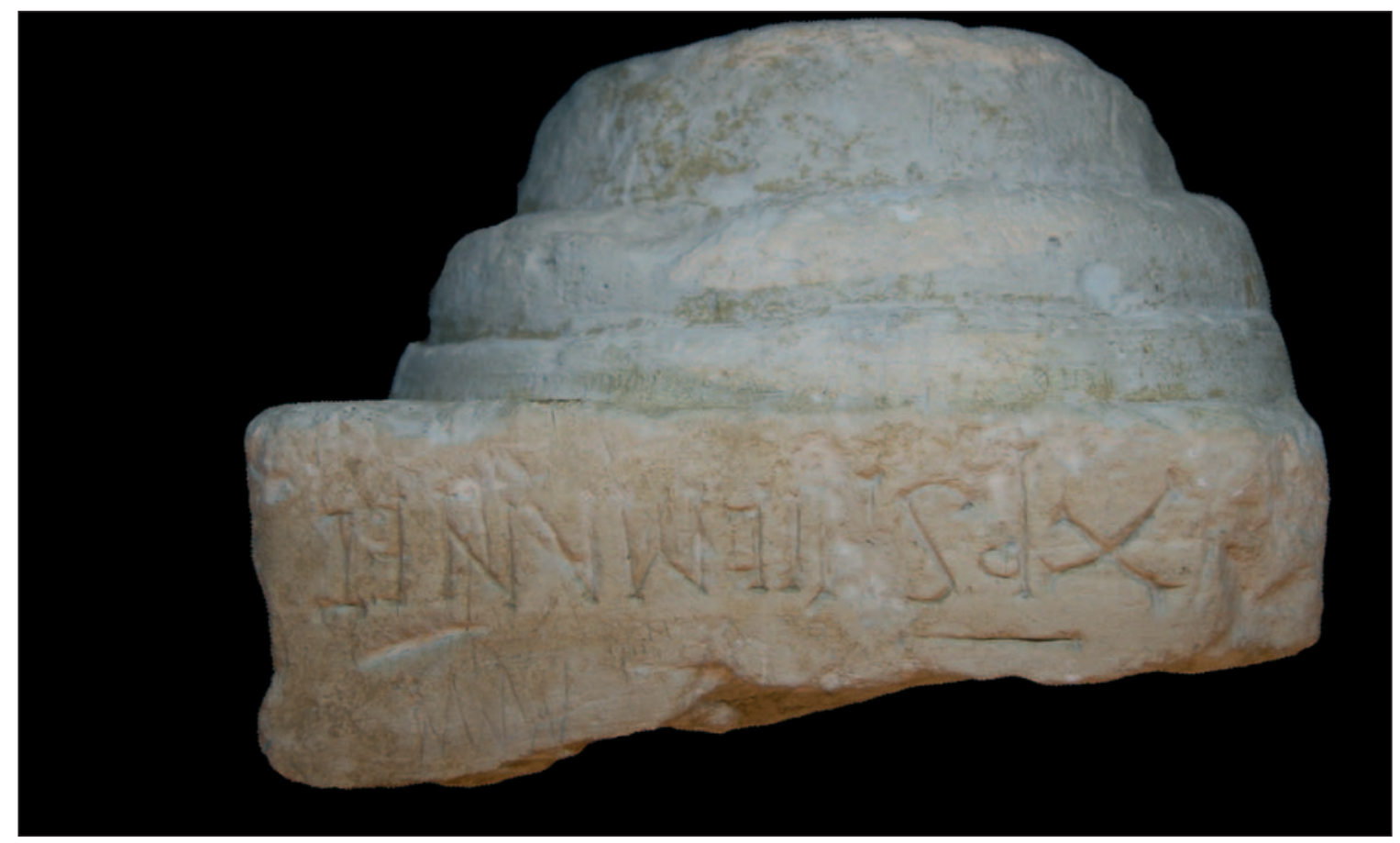

Figura 1. $\mathrm{N}^{\mathrm{o}}$ 1. Basa romana utilizada como capitel medieval. Sector de Puerta Obispo. 


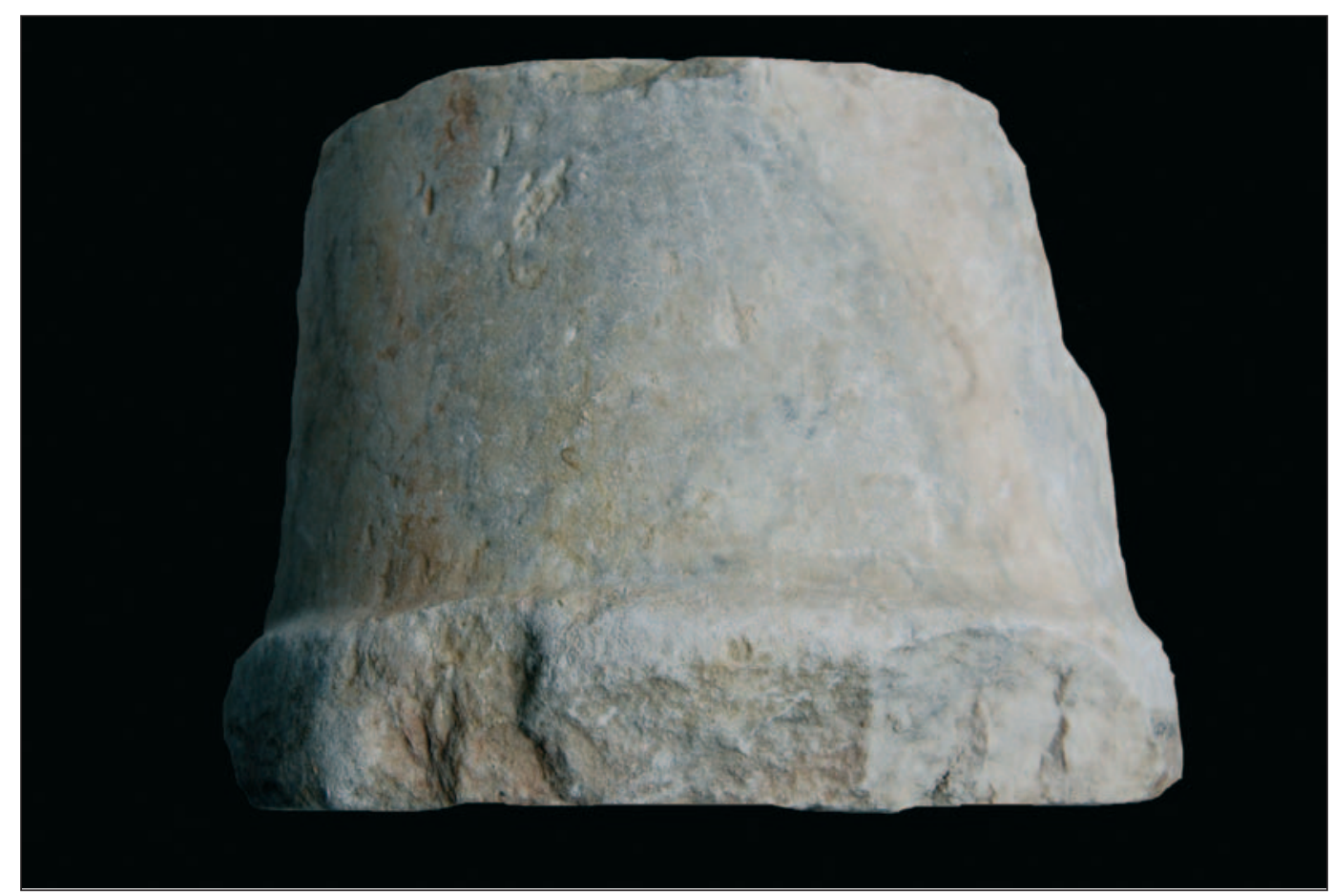

Figura 2. № 2. Semicolumna. Sector de Puerta Obispo.

\section{FUSTES}

2.- N $^{\circ}$ inv.: $2004 / 20 / C$; subsector Termas; UE 5012.

Dimensiones: 24,7 x $17,5 \times 10 \mathrm{~cm}$

Fragmento de semicolumna adosada con basa simple y fuste liso, tallado en mármol de color gris con vetas azuladas de grano finomedio (Fig. 2). En la parte inferior de la basa, la zona interna está rehundida para facilitar la adherencia de la pieza a la pared mediante argamasa.

3.- $\mathrm{N}^{\circ}$ inv.: $2004 / 20 / \mathrm{J}$; subsector Termas; UE 5012.

Dimensiones: 90 x $26 \mathrm{~cm}$ (aprox.)

Fuste de columna de caliza de Espejón, de tonalidad violácea brechada en amarillo, cortada transversalmente a la dirección de la veta (Fig. 3).

4.- $\mathrm{N}^{\circ}$ inv.: $2004 / 20 / \mathrm{J} / 2$; subsector Termas; UE 5012.

Dimensiones: 15,2 × 9,2 × $3 \mathrm{~cm}$

Fragmento de columna de caliza de Espejón de tonalidad violácea brechada en amarillo (Fig. 2). Pertenece a la pieza anterior.

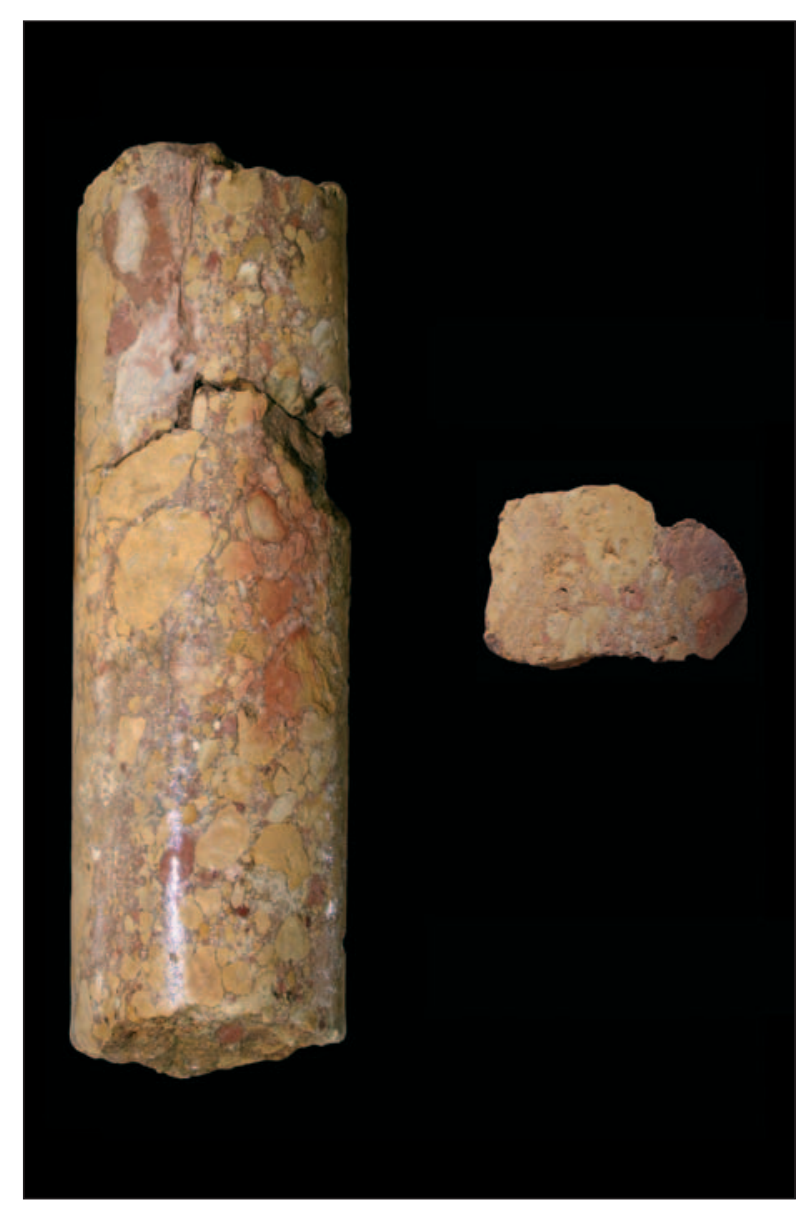

Figura 3. $\mathrm{N}^{\circ} 3$ y 4 . Fuste y fragmento de columna de caliza de Espejón. Sector de Puerta Obispo. 


\section{Cornisas}

5.- $\mathrm{N}^{\circ}$ inv.: 2004/20/1147/19; subsector Calle; UE 1147.

Dimensiones: 18 x 7,7 x $5 \mathrm{~cm}$

Fragmento de cornisa incompleta, que ha perdido toda la parte inferior. Está realizada en mármol blanco de grano fino-medio (Fig. 4).

6.- $\mathrm{N}^{\circ}$ inv.: 2004/20/E; subsector Termas; UE 5012.

Dimensiones: $21 \times 8 \times 7 \mathrm{~cm}$

Fragmento de posible cornisa. En la parte superior se aprecia un resalte que pudo haber servido como tope a una placa superior. Está realizada en mármol blanco de grano finomedio. Tiene una marca formada por dos trazos verticales unidos por uno horizontal, en forma de "H" alargada (Fig. 4).

7.- $\mathrm{N}^{\circ}$ inv.: 2004/20/F; subsector Termas; UE 5012.

\section{Dimensiones: 12 x 4 x $5 \mathrm{~cm}$}

Fragmento de cornisa de esquina, que presenta tres caras talladas de forma plana sin alisado y con incisiones diagonales para facilitar su fijación. La cara inferior, donde encajaría la placa marmórea, presenta una marca a mano alzada con dos trazos cruzados en forma de " $X$ ". La cara vista es moldurada. Está realizada en mármol blancogrisáceo de grano fino-medio con veteado en gris (Fig. 4).

8.- $\mathrm{N}^{\circ}$ inv.: 2004/20/F2; subsector Termas; UE 5012.

Dimensiones: $23,3 \times 7 \times 7 \mathrm{~cm}$

Fragmento de cornisa realizada en mármol blanco de grano fino-medio. Conserva el perfil completo. En la parte inferior se aprecian dos perforaciones de sección circular de unos $2 \mathrm{~cm}$ de profundidad separadas entre sí por 2, $8 \mathrm{~cm}$ (Fig. 4).
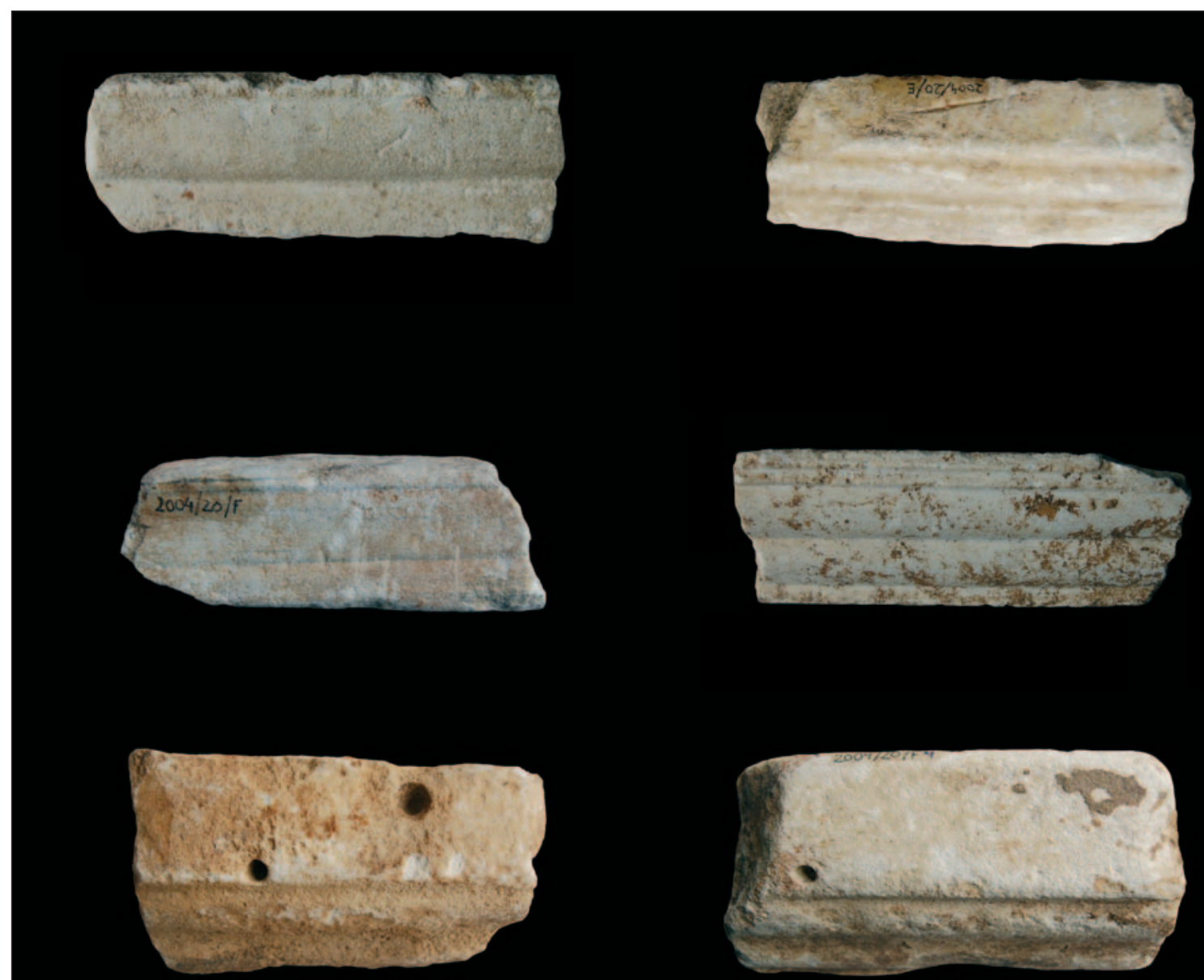

Figura 4. № 5 - 10. Cornisas de mármol. Sector de Puerta Obispo. 
9.- $\mathrm{N}^{\circ}$ inv.: 2004/20/F3; subsector Termas; UE 5012.

Dimensiones: $19,2 \times 10 \times 6 \mathrm{~cm}$

Fragmento de cornisa realizada en mármol blanco de grano fino-medio. En la parte inferior se aprecian dos agujeros para sujeción, de aproximadamente $1 \mathrm{~cm}$ de profundidad. La pieza parece cortada intencionadamente en un momento posterior (Fig. 4).

10.- $\mathrm{N}^{\circ}$ inv.: 2004/20/F4; subsector Termas; UE 5012.

Dimensiones: $17,8 \times 11 \times 7 \mathrm{~cm}$

Fragmento de cornisa realizada en mármol blanco de grano fino-medio. Conserva una perforación en la parte trasera, con cierta inclinación, que pudo ser usada para fijar la pieza de mármol a una pared mediante un perno metálico. En la parte inferior de la cara delantera tiene otra perforación. En la superficie plana ancha conserva restos del trabajo de la gradina (Fig. 4).

\section{Placas}

11.- $\mathrm{N}^{\circ}$ inv.: 2004/20/1020/20; subsector Puerta; UE 1020.

Dimensiones: 16,9 x $11,5 \times 2,5 \mathrm{~cm}$

Fragmento de placa de pavimento o revestimiento de mármol gris con vetas negras, de grano medio. La superficie exterior no está pulimentada y presenta uno de sus lados realzado (Fig. 5).

12.- $\mathrm{N}^{\mathrm{o}}$ inv.: 2004/20/1026/02; subsector Puerta; UE 1026 .

Dimensiones: 12 × $7,7 \times 1,8 \mathrm{~cm}$

Fragmento de placa de mármol blanco de grano fino-medio (Fig. 5).

13.- $\mathrm{N}^{\text {o }}$ inv.: 2004/20/1028B/38; subsector Puerta; UE 1028B.

Dimensiones: 14,5 × 8,5 × $2 \mathrm{~cm}$ y 7 x 4 x 2 $\mathrm{cm}$

Dos fragmentos de placa de mármol de color blanco con vetas grises, de grano medio (Fig. 5).

14.- $\mathrm{N}^{\mathrm{o}}$ inv.: 2004/20/1035/07; subsector Puerta; UE 1035 .

Dimensiones: $6,3 \times 3 \times 4 \mathrm{~cm}$
Fragmento de placa de revestimiento parietal. La cara vista se encuentra perfectamente pulida, mientras en la cara posterior se observan surcos realizados con el objetivo de facilitar la fijación a la pared mediante mortero o argamasa. Está realizada en mármol grisáceo de grano fino con vetas azuladas (Fig. 5).

15.- $\mathrm{N}^{\circ}$ inv.: 2004/20/1090/22; subsector Puerta; UE 1090.

Dimensiones: $20 \times 7 \times 2 \mathrm{~cm}$

Placa de mármol de color gris con vetas azuladas de grano medio, rota en dos fragmentos (Fig. 5).

16.- $\mathrm{N}^{\text {o }}$ inv.: 2004/20/1090/22/2; subsector Puerta; UE 1090.

Dimensiones: $10,5 \times 6,3 \times 1,8 \mathrm{~cm}$ y $9,4 \mathrm{x}$ $6,6 \times 1,7 \mathrm{~cm}$

Placa marmórea de color gris con vetas de color negro azulado y grano medio, rota en dos fragmentos (Fig. 5).

17.- $\mathrm{N}^{\circ}$ inv.: 2004/20/1104/08; subsector Calle; UE 1104.

Dimensiones: 4,3 x 4 x 2,3 cm

Pequeño fragmento de placa de mármol de color blanco con vetas grisáceas de grano fino-medio (Fig. 5).

18.-N ${ }^{\circ}$ Inv.: 2004/20/1116/19; subsector Calle; UE 1116.

Dimensiones: $20 \times 9,7 \times 2 \mathrm{~cm}$

Fragmento de placa de mármol grisáceo veteado en negro, de grano medio. Presenta ambas caras perfectamente pulimentadas y el canto biselado (Fig. 5).

19.-N ${ }^{\circ}$ inv.: 2004/20/1119/10; subsector Puerta; UE 1119.

Dimensiones: $8,6 \times 7,8 \times 2,6 \mathrm{~cm}$

Fragmento de placa de mármol blanco con vetas grises, de grano fino-medio (Fig. 5).

20.-No inv.: 2004/20/4010/31; subsector Calle; UE 4010.

Dimensiones: $9,2 \times 6,8 \times 3 \mathrm{~cm}$

Fragmento de placa de revestimiento. Está realizada en mármol blanco-grisáceo de grano fino-medio (Fig. 5). 


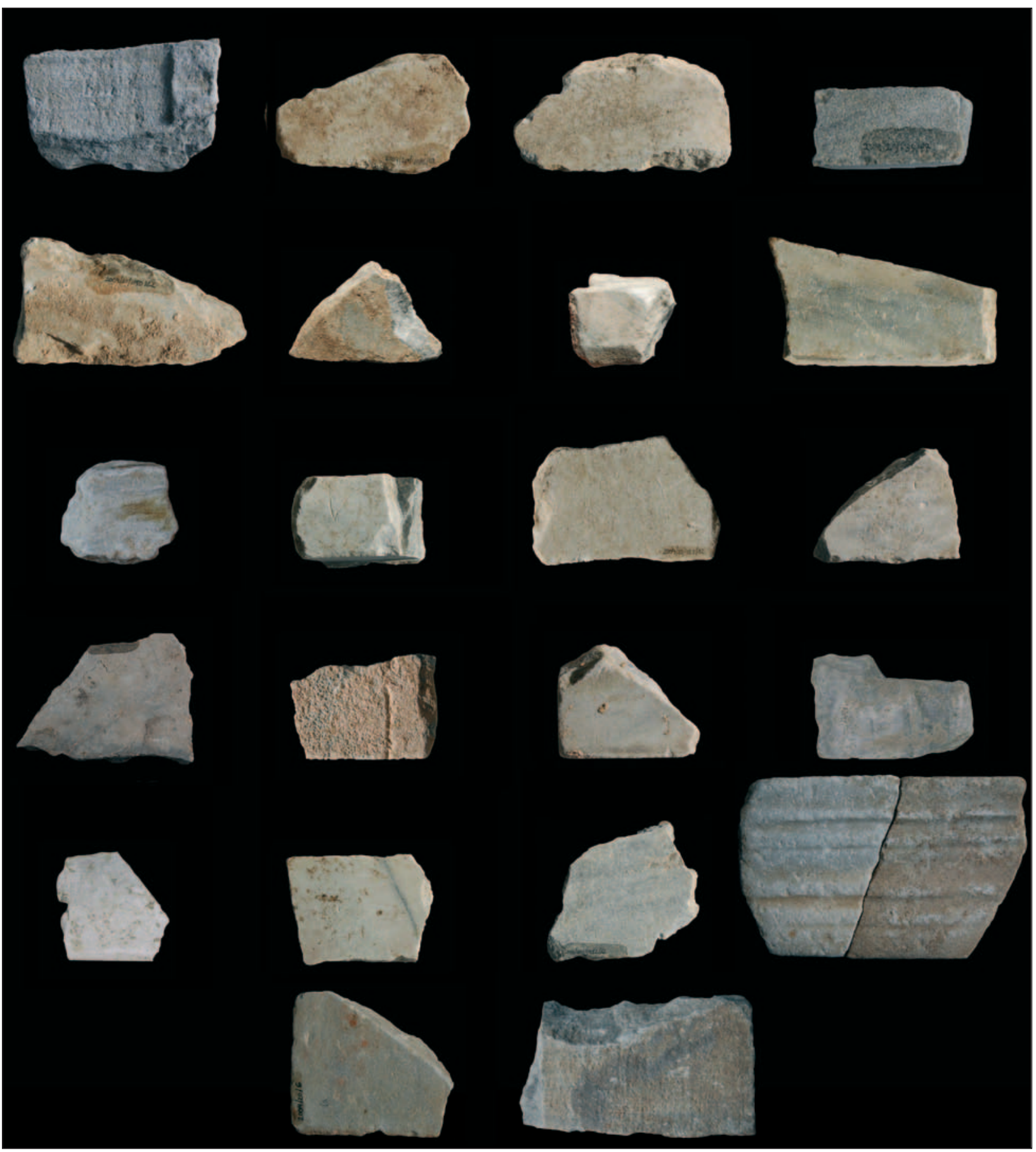

Figura 5. № 11-32. Crustae de mármol. Sector de Puerta Obispo.

21.- $\mathrm{N}^{\mathrm{o}}$ inv.: 2004/20/4011/02; subsector Termas; UE 4011 .

Dimensiones: 14,2 × 7,4 x 2,6 cm

Fragmento de placa de mármol blanco de grano medio (Fig. 5).

22.- $\mathrm{N}^{\mathrm{o}}$ inv.: 2004/20/4019/13; subsector Calle; UE 4019.

Dimensiones: $8,6 \times 6 \times 3 \mathrm{~cm}$
Fragmento de placa de pavimento de mármol gris con vetas azuladas, de grano medio (Fig. 5).

23.- $\mathrm{N}^{\mathrm{o}} \quad$ inv.: 2004/20/4021/24; $\quad$ subsector Termas/Muralla; UE 4021.

Dimensiones: 16 x 12,4 x 4 cm

Fragmento de placa de mármol rosado con vetas blanquecinas y grano medio. Presenta la superficie exterior pulimentada y la cara inferior apenas desbastada para facilitar su fijación (Fig. 5). 
24.- $\mathrm{N}^{\mathrm{o}} \quad$ inv.: 2004/20/4021/25; subsector Termas/Muralla; UE 4021.

Dimensiones: $10,5 \times 7,3 \times 3,2 \mathrm{~cm}$

Fragmento de placa de color gris oscuro (Fig. 5).

25.- $\mathrm{N}^{\mathrm{o}} \quad$ inv.: 2004/20/4021/26; subsector Termas/Muralla; UE 4021.

Dimensiones: $7,1 \times 6,5$ × $2 \mathrm{~cm}$

Fragmento de placa de mármol de color grisáceo de grano medio, con la superficie bien pulimentada (Fig. 5).

26.- $\mathrm{N}^{\circ}$ inv.: 2004/20/4026/23; subsector Puerta; UE 4026.

Dimensiones: $13 \times 11,7$ x $3 \mathrm{~cm}$

Fragmento de placa de revestimiento realizada en mármol de grano fino de color gris con vetas de color más azulado, procedente de Estremoz ${ }^{2}$ (Fig. 5).

27.- $\mathrm{N}^{\circ}$ inv.: 2004/20/4040/30; subsector Calle; UE 4040.

Dimensiones: $8 \times 7,3 \times 2,5 \mathrm{~cm}$

Fragmento de placa de revestimiento marmóreo de grano fino y de color blanco grisáceo que presenta un bandeado de color gris más oscuro. En su parte posterior presenta un orificio de fijación. Procede de Estremoz ${ }^{3}$ (Fig. 5).

28.- $\mathrm{N}^{\circ}$ inv.: 2004/20/4048/25; subsector Calle; UE 4048 .

Dimensiones: $11,9 \times 9,1 \times 1,5 \mathrm{~cm}$

Fragmento de placa de revestimiento parietal realizada en mármol blanco con vetas grises y grano medio. La superficie vista está bien pulimentada mientras la interior está apenas desbastada (Fig. 5).

29.- $\mathrm{N}^{\circ}$ inv.: 2004/20/5012/12; subsector Termas; UE 5012.
Dimensiones: $12,5 \times 9 \times 1,5 \mathrm{~cm}$

Fragmento de placa de mármol grisáceo veteado en negro (Fig. 5).

30.- $\mathrm{N}^{\circ}$ inv.: 2004/20/D, subsector Termas; UE 5012.

Dimensiones: 34,5 x $20,7 \times 3 \mathrm{~cm}$

Fragmentos pertenecientes a una placa de revestimiento parietal, exteriormente decorada con molduras verticales. En la cara posterior se aprecia el tratamiento de la superficie mediante surcos diagonales para facilitar la adherencia de la argamasa a la pared. Tal vez formó parte de la embocadura de una puerta. Está realizada en mármol blanco-grisáceo de grano fino-medio (Fig. 5).

31.- $\mathrm{N}^{\circ}$ inv.: 2004/20/G; subsector Termas; UE 5012.

Dimensiones: $14,5 \times 12 \times 2,2 \mathrm{~cm}$

Fragmento correspondiente a la esquina de una placa de revestimiento marmóreo de tonalidad grisácea, con vetas azuladas, de grano fino. Los laterales están rebajados en el reverso para trabar mejor la argamasa de sujeción (Fig. 5).

32.- $\mathrm{N}^{\circ}$ inv.: 2004/20/5/CN/10; Nivel de Limpieza.

Dimensiones: 19,7 x 11,5 x 2,2 cm

Fragmento perteneciente a una placa de revestimiento parietal. En uno de los extremos de la cara vista se aprecia un retalle rectangular, sin duda para fijar otra placa o moldura transversal. En la cara posterior se aprecian el tratamiento de la superficie mediante surcos diagonales para facilitar la adherencia de la argamasa a la pared, de la que se conservan restos. Está realizada en mármol grisáceo de grano fino-medio, con vetas más azuladas (Fig. 5).
2 Rodà, I., Àlvarez, A., Gutiérrez García-Moreno, A. \& Domènech, A. (2009): Informe del análisis de 3 muestras de marmora procedentes de las termas legionarias de León,
Unitat d'Estudis Arqueomètrics, ICAC, Tarragona. Vid apéndice.

3 Ibid. 


\section{FRAGMENTOS INDETERMINADOS}

33.- $\mathrm{N}^{\mathrm{o}} \quad$ inv.: $2004 / 20 / 4021 / 23$; subsector Termas/Muralla; UE 4021.

Dimensiones: 13,3 x 10 x 7,3 cm

Fragmento de piedra arenisca gris con restos de decoración figurada en tres de las cuatro caras, que aparecen con dos molduras en su parte inferior (Fig. 6). En los dos lados mayores se repite un mismo elemento indeterminado en relieve enmarcado dentro de un círculo. En uno de los lados menores se reconoce un motivo vegetal.

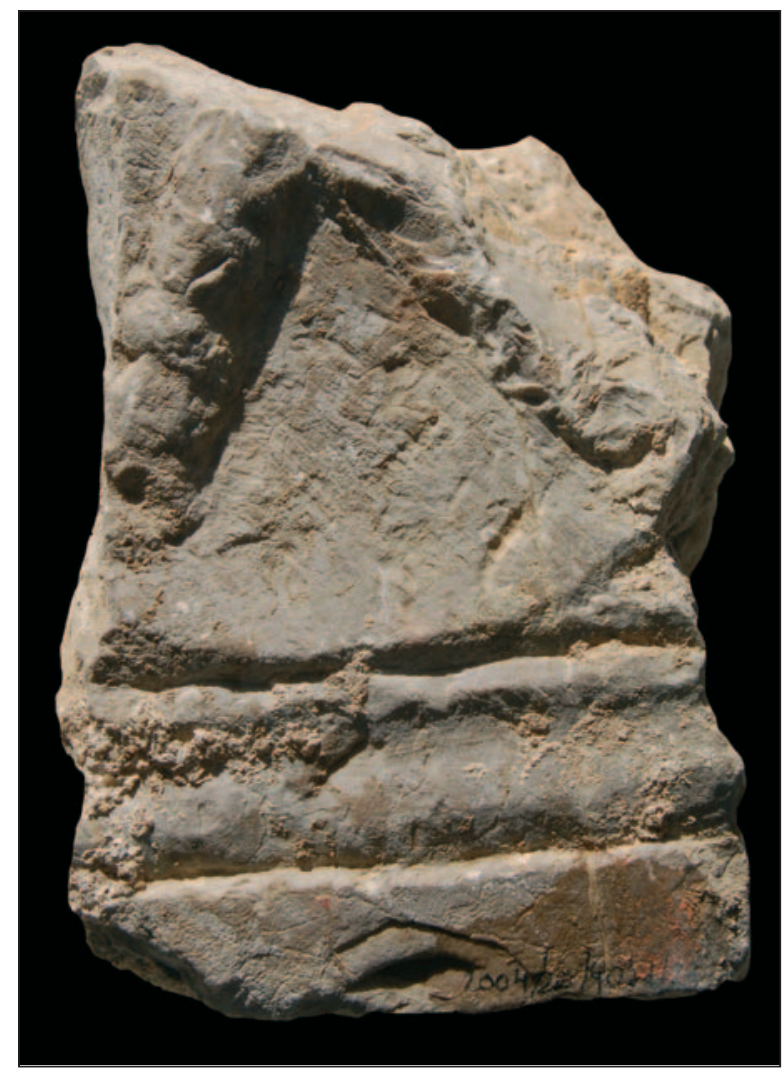

Figura 6. $\mathrm{N}^{\mathrm{o}}$ 33. Fragmento de caliza con restos de decoración figurada. Sector de Puerta Obispo.

\section{PLAZA DE PUERTA OBISPO $\mathrm{N}^{\circ} 8$ Y PLAZA DE SAN PEDRO No 9}

En las intervenciones desarrolladas por la empresa Talactor en el solar comprendido entre la plaza de Puerta Obispo, ${ }^{\circ} 8$ y la plaza de San Pedro, $\mathrm{n}^{\circ} 9$, a escasa distancia extramuros de la puerta principalis sinistra del campamento, apareció una basa de columna que pasamos a describir.

\section{4.- $\mathrm{N}^{\mathrm{o}}$ inv.: 2008/31/1; UE 31.}

Dimensiones: Alt. Máxima $31 \mathrm{~cm}$.; Diám.: 30 cm.; Alt. plinto: $7 \mathrm{~cm}$; Diám. toro: $27 \mathrm{~cm}$; Diám. imoscapo: $22 \mathrm{~cm}$.

Basa toscana de columna con plinto, unido directamente al toro de perfil en arco de circunferencia de gran abertura, seguido de un caveto (Figs. 7a y b).

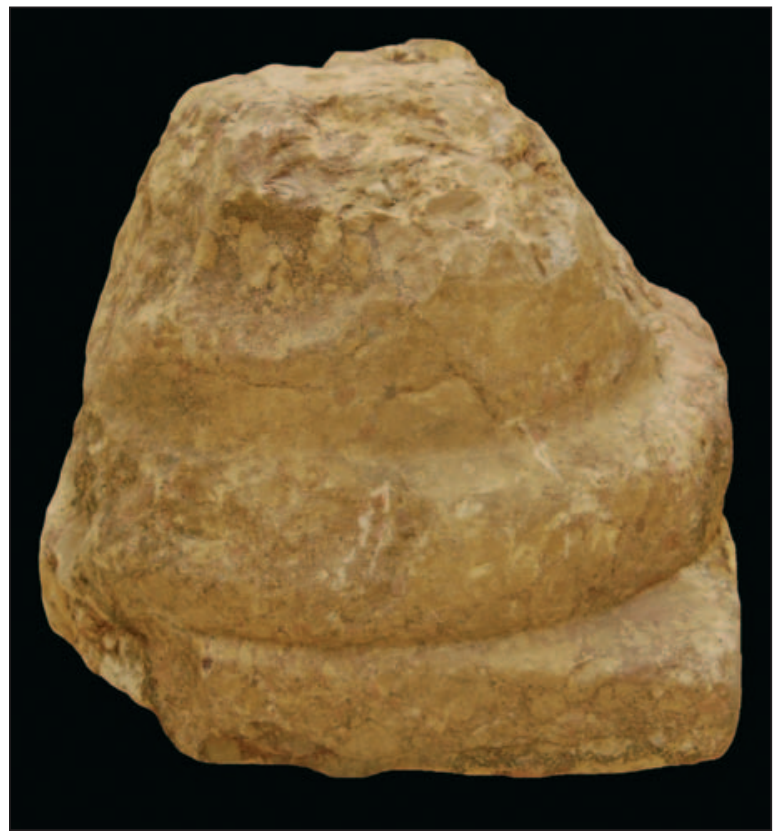

Figura 7a. № 34 . Basa de piedra de Espejón. Plaza de Puerta Obispo $n^{\circ} 8$ c/v plaza de San Pedro $n^{\circ} 9$.

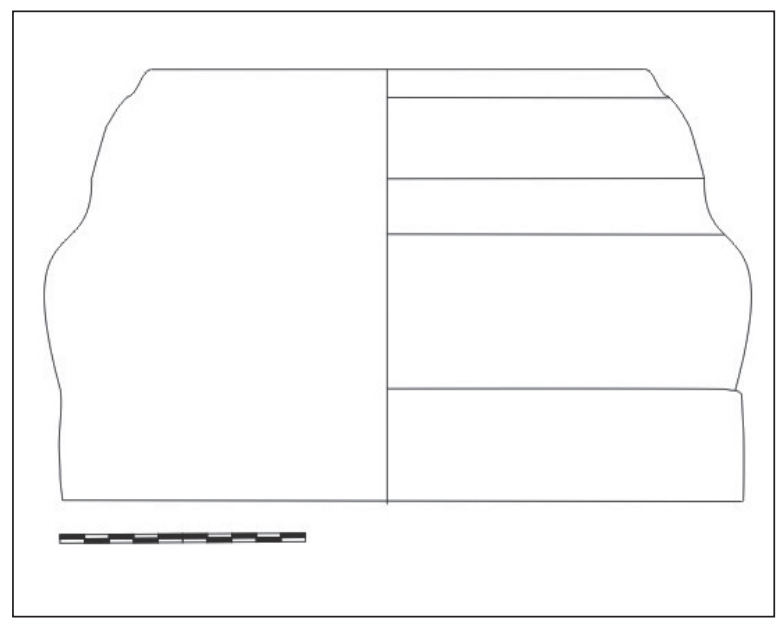

Figura 7b. $\mathrm{N}^{\circ}$ 34. Perfil de la anterior. Plaza de Puerta Obispo $\mathrm{n}^{\circ} 8 \mathrm{c} / \mathrm{v}$ plaza de San Pedro $\mathrm{n}^{\circ} 9$

El material empleado es caliza brechada de Espejón, de tonalidad violácea. 


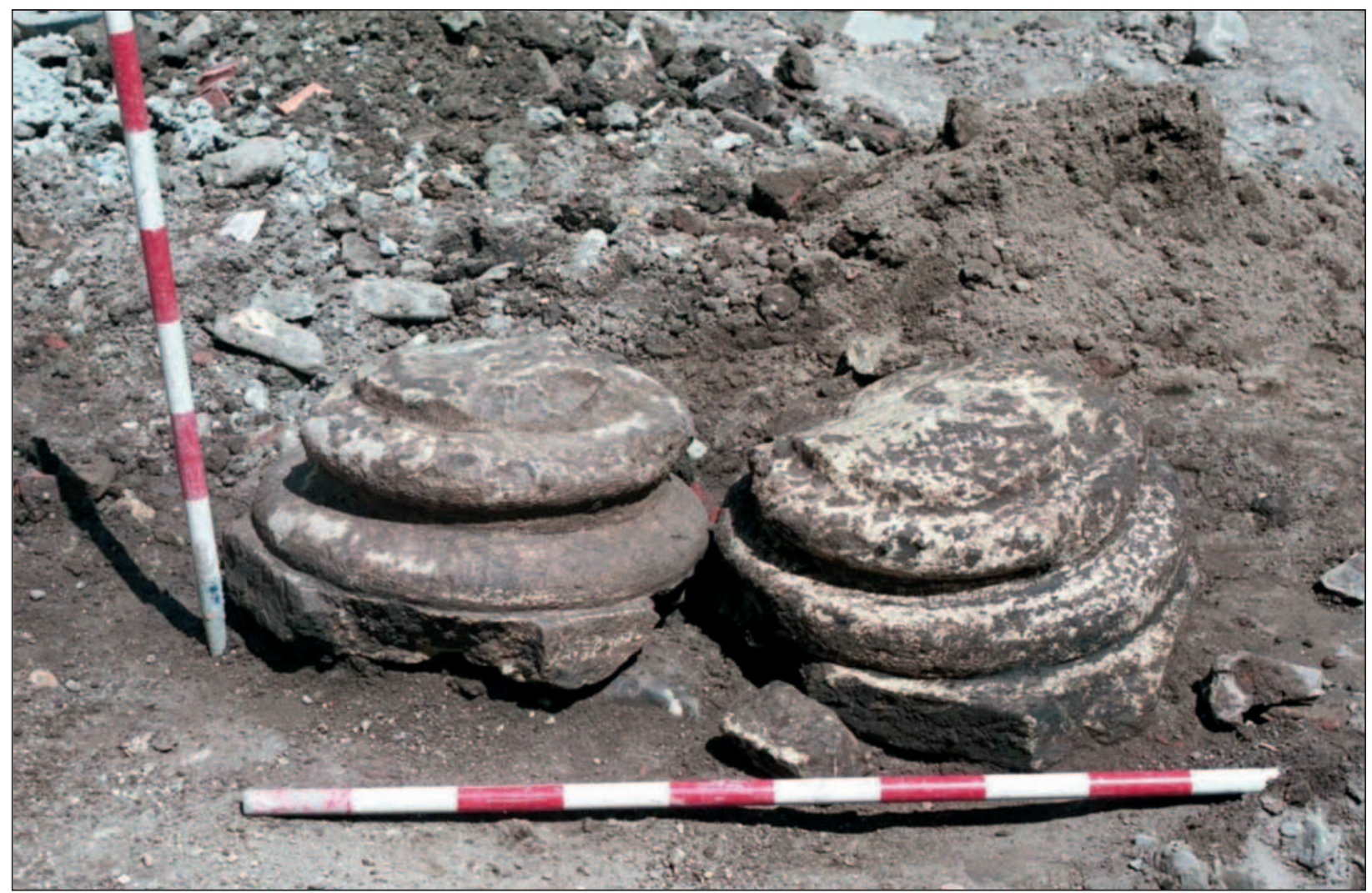

Figura 8. $\mathrm{N}^{\mathrm{o}} 35$ y 36. Posición in situ de las dos basas procedentes de la calle Dámaso Merino $\mathrm{n}^{\mathrm{o}} 6$ (Fotografía: V. García Marcos).

\section{CALLE DÁMASO MERINO Nº 6}

Durante la intervención de urgencia desarrollada en 1994 por V. García Marcos en el número 6 de la calle Dámaso Merino de León, se documentó parte de un espacio porticado que, asociado a un colector sanitario, formaba parte del cierre meridional del patio de los principia del campamento de la legio VII gemina (Morillo \& García Marcos, 2006: 252). Una vez concluida la excavación, durante las labores de cimentación del edificio que actualmente ocupa el solar, se recuperaron dos de las basas del pórtico (Fig. 8).

35.- $\mathrm{N}^{\mathrm{o}}$ inv.: 2005/47/119; Recuperada durante las labores de cimentación (Fig. 9).

Dimensiones: Alt. 26,5 cm.; Diám.: $50 \mathrm{~cm}$; Alt. plinto: $7,5 \mathrm{~cm}$; Diám. toro inferior: 50 $\mathrm{cm}$; Diám. escocia: $45 \mathrm{~cm}$; Diám. toro superior: $47 \mathrm{~cm}$; Diám. imoscapo: $29 \mathrm{~cm}$.

Basa ática de columna con plinto seguido de un toro. A continuación se dispone una escocia alta y profunda y un segundo toro de perfil semicircular. La pieza está rematada por un listel y un imoscapo liso.

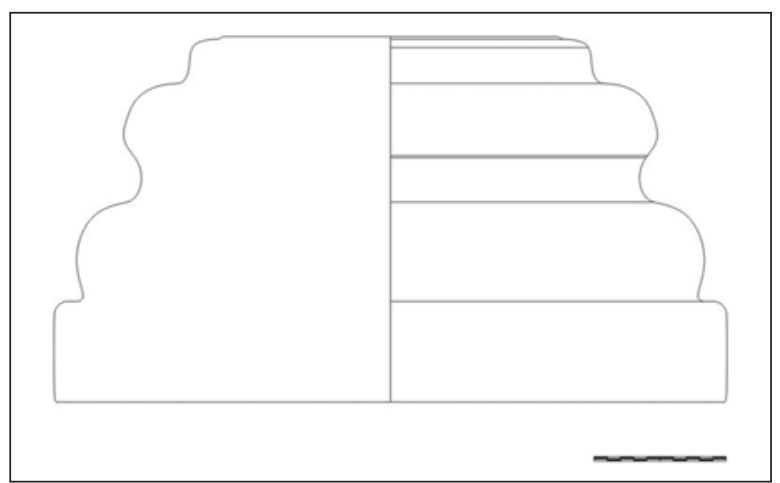

Figura 9. № 35. Basa ática. Calle Dámaso Merino $\mathrm{n}^{\circ} 6$.

El material empleado es caliza local.

36.- $\mathrm{N}^{\mathrm{o}}$ inv.: 2005/47/120; Recuperada durante las labores de cimentación (Fig. 10).

Dimensiones: Alt. 31 cm.; Diám.: 52 cm.; Alt. plinto: $8 \mathrm{~cm}$; Diám. toro inferior: $48,5 \mathrm{~cm}$; Diám. escocia: $42 \mathrm{~cm}$; Diám. toro superior: $44,5 \mathrm{~cm}$; Diám. imoscapo: $29 \mathrm{~cm}$.

Basa ática de columna de fisonomía y dimensiones muy semejantes a la anterior. Es de tipo ático, con plinto seguido de un toro, 
escocia profunda y un segundo toro de perfil en cuarto de bocel levemente deformado. Un listel da paso en ángulo recto al imoscapo liso.

También en este caso se emplea como material la caliza local.

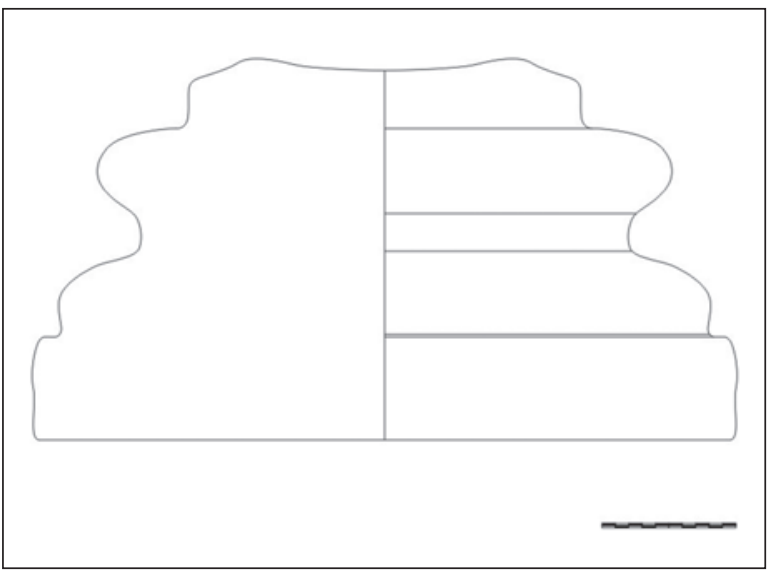

Figura 10. $\mathrm{N}^{\circ}$ 36. Basa ática.

Calle Dámaso Merino n ${ }^{\circ} 6$.

\section{CALLE SANTA MARINA}

Las obras de reurbanización (plan E) de la ciudad antigua llevadas a cabo en el año 2010 tuvieron como consecuencia la apertura del firme de la calle Santa Marina casi en la esquina con la calle San Alvito, junto a la gran parcela excavada durante el año 1996 en el sector norte de la ciudad. El hallazgo más significativo fue el de una basa de pilastra en caliza in situ, cuyos rasgos presentamos a continuación (Fig. 11 y 12).

\section{7.- $\mathrm{N}^{\mathrm{o}}$ inv.: 2010/1113/20; UE 1113}

Dimensiones: Alt. $36 \mathrm{~cm}$.; Longitud conservada: $50 \mathrm{~cm}$.; anchura: $50 \mathrm{~cm}$.

Basa de pilastra cuadrangular, parcialmente conservada. La rotura de la pieza durante la extracción hace muy difícil determinar sus dimensiones exactas. Presenta una superficie de apoyo inferior de unos $40 \mathrm{~cm}$ de lado, sobre la que se dispone un plinto de $6 \mathrm{~cm}$ de altura, una escocia que se retrae $2,5 \mathrm{~cm}$ respecto al plano del plinto, dos toros con una escocia intermedia, un listel y la superficie de apoyo de la pilastra, de $42 \mathrm{~cm}$ de lado.

La pieza está tallada en caliza local que, debido a la gran humedad del terreno y a su fragilidad, se fracturó en numerosos fragmentos durante su extracción.

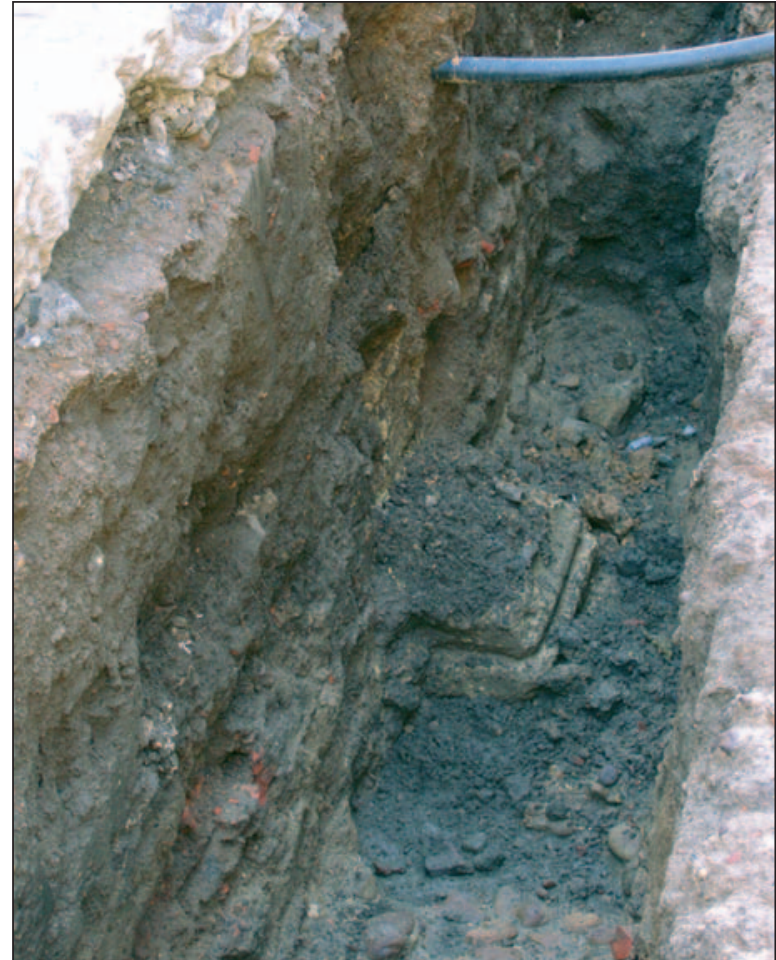

Figura 11. $\mathrm{N}^{\mathrm{o}}$ 37. Descubrimiento de la basa de pilastra aparecida in situ. Calle Santa Marina

(Fotografía: V. García Marcos).

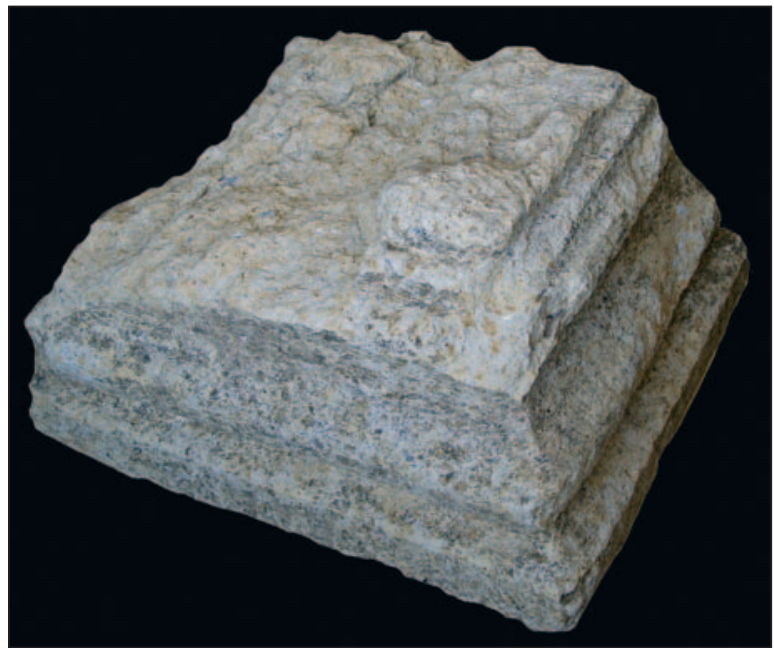

Figura 12. $\mathrm{N}^{\circ} 37$. Basa de pilastra Calle Santa Marina

\section{CALLE CONDE LUNA No 9}

Durante 2010, las obras de acondicionamiento del entramado viario derivadas del denominado plan E, dirigidas por V. García Marcos, Arqueólogo Municipal de León, pusieron al descubierto delante del $\mathrm{n}^{\circ} 9$ de la calle Conde Luna (sondeo $\mathrm{n}^{\circ} 12$ ) una basa romana completa, que se encontraba todavía en su posición original, formando parte de un pórtico (Figs. 13a-c). 


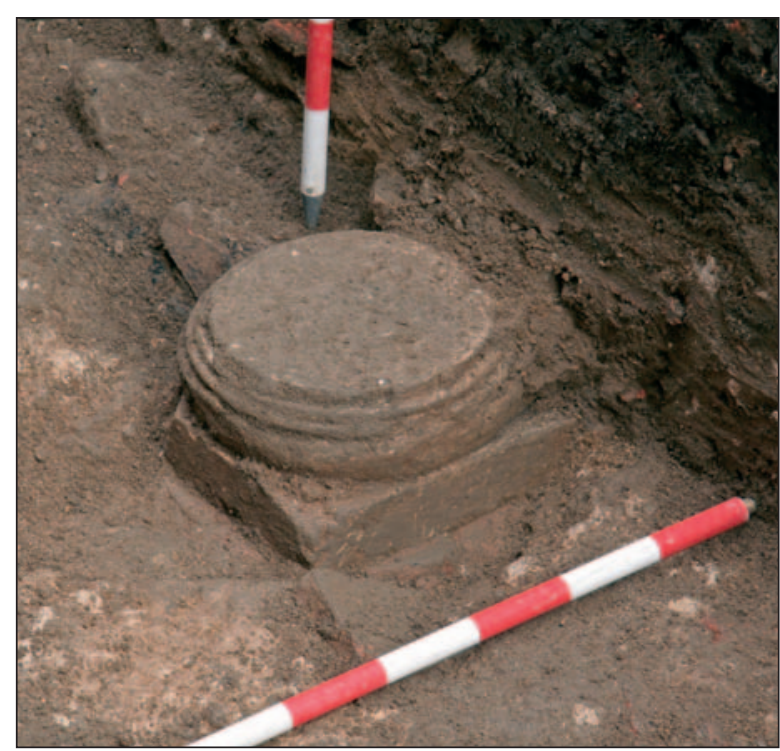

Figura 13a. $\mathrm{N}^{\circ}$ 38. Posición in situ de la basa encontrada en la intervención de la calle Conde Luna $n^{\circ} 9$ (Fotografía: V. García Marcos)

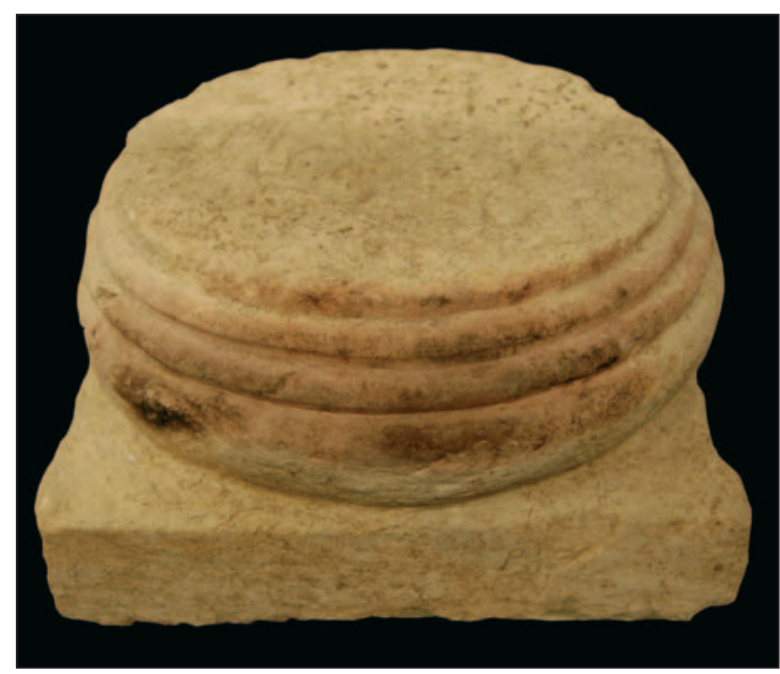

Figura 13b. $\mathrm{N}^{\mathrm{o}} 38$. Basa procedente de la calle Conde Luna ${ }^{\circ} 9$.

38.- $\mathrm{N}^{\mathrm{o}}$ inv.: 2010/12012/5; UE 12012.

Dimensiones: Alt.: 17, 3 cm.; Diám.: 29,5 cm.; Alt. plinto: $7 \mathrm{~cm}$; Diám. toro: $29 \mathrm{~cm}$; Diám. imoscapo: $28 \mathrm{~cm}$.

Basa toscana de columna con plinto estrecho, unido directamente al toro, de perfil en arco de circunferencia de gran abertura, seguido de dos listeles. La pieza se encontraba firmemente asentada sobre un basamento realizado mediante ladrillos de cuarto de círculo perfectamente ensamblados, que sobresalían bajo el plinto $2 \mathrm{~cm}$ por cada lado, aislando la piedra de la humedad del terreno.

El material empleado es caliza local.

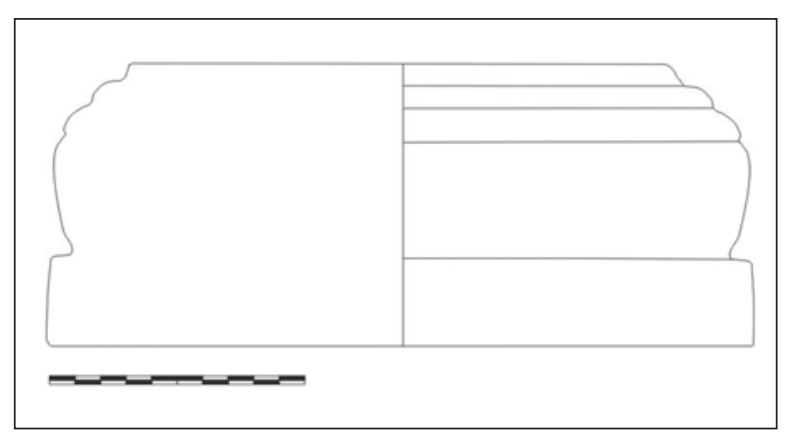

Figura $13 c . \mathrm{N}^{\circ} 38$. Perfil de la basa anterior. Calle Conde Luna $n^{\circ} 9$.

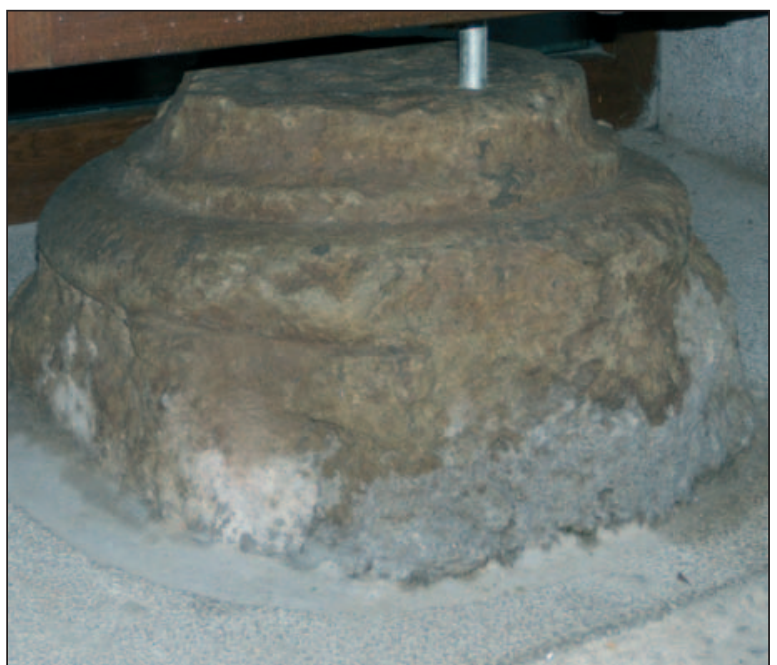

Figura 14. № 39 . Posición actual de la basa. Calle Serradores $n^{\circ} 2$

\section{CALLE SERRADORES $\mathbf{N}^{\circ} 2$}

En la calle Serradores se halla en la actualidad una basa de época romana que decora la fachada del bar La Calea (Fig. 14).

39.- Sin $n^{\circ}$ inventario.

Dimensiones: Alt. 19,5 cm; Diám.: $27 \mathrm{~cm}$; Alt. plinto: $11 \mathrm{~cm}$; Diám. toro: $25 \mathrm{~cm}$; Diám. imoscapo: $18 \mathrm{~cm}$.

Basa toscana de columna con plinto muy alto, toro de perfil en arco de circunferencia de gran abertura, rematado con un listel en la parte superior.

De nuevo en este caso el material constructivo es caliza local.

\section{CALLE DON GUTIERRE No 4, 6,8 Y 10}

Con motivo de una intervención realizada por la empresa Specum S. L. en 2005 ingresaron en el Museo de León las dos piezas que aquí presentamos. No se conocen otros materiales ni informe de excavación. 
40.- $\mathrm{N}^{\text {o }}$ inv. 2004/6; Descontextualizado.

Dimensiones: Alt. cálato $52 \mathrm{~cm}$; Alt. ábaco: 6 $\mathrm{cm}$; Diám. superior fuste conservado: $25 \mathrm{~cm}$; Diám. superior 37; lado ábaco: $45 \mathrm{~cm}$.

Fragmento de capitel corintio retallado en época posterior para ser reutilizado como material constructivo, trabajo que casi ha hecho desaparecer la decoración de la pieza (Fig. 15). Se aprecian dos coronas superpuestas de hojas de acanto, la inferior prácticamente desaparecida, mientras la superior se conserva algo mejor. Las hojas están recorridas por una gran nervadura central incisa, prolongándose el surco central hasta la base del capitel. Los caulículos han desaparecido casi por completo, al igual que las hélices y volutas superiores.

El material constructivo es caliza local.

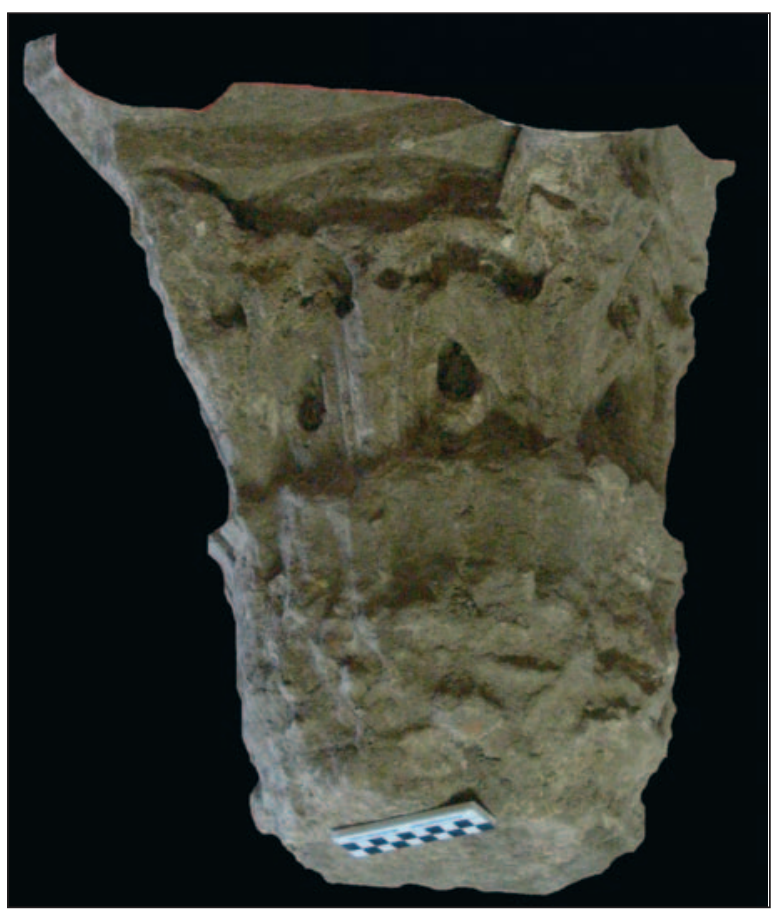

Figura 15. N$^{\circ}$ 40. Capitel corintio. Calle Don Gutierre no 4-10 (Fotografía Miryam Hernández Valverde)

41.- $\mathrm{N}^{\mathrm{o}}$ inv. 2004/6; Descontextualizado.

Dimensiones: Alt.: $28 \mathrm{~cm}$; Diám.: $25 \mathrm{~cm}$.

Fragmento de fuste liso realizado en piedra caliza.

\section{PLAZA DE DON GUTIERRE}

En los fondos antiguos del Museo de León se conserva una pieza procedente al parecer de la plaza de Don Gutierre, sin que tengamos más datos sobre las circunstancias de aparición.

42.- $\mathrm{N}^{\circ}$ inv. 2899. Descontextualizado.

Dimensiones: Alt.: 47cm; Diám.: $83 \mathrm{~cm}$.

Gran tambor perteneciente a una columna estriada, achatado en uno de sus extremos, lo que indica claramente que actuó como pilastra adosada a un muro, tallado en piedra caliza (Fig. 16).

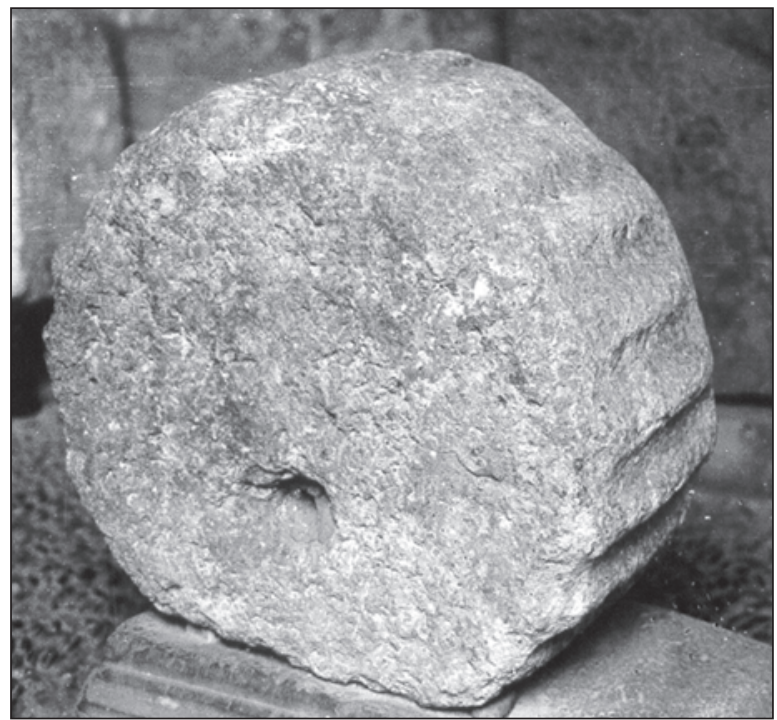

Figura 16. $\mathrm{N}^{\mathrm{o}} 42$. Tambor de columna. Plaza de Don Gutierre

\section{SECTOR OESTE DE LA MURALLA}

También entre los fondos antiguos del Museo se constata la presencia de una pieza recogida seguramente en el sector oeste de la muralla, junto al palacio de los Guzmanes, ya que su hallazgo se asocia con la Puerta Cauriense, correspondiente a la porta principalis dextra del recinto romano.

43.- $\mathrm{N}^{\circ}$ inv. 2888. Descontextualizado.

Dimensiones: Long.: $99 \mathrm{~cm}$; Anch.: $67 \mathrm{~cm}$; Alt.: $30 \mathrm{~cm}$.

Gran sillar identificado como parte de un dintel o entablamento (Fig. 17). La presencia de molduras en sus dos lados largos y estrechos, así como la superficie curva en uno de sus extremos cortos y, sobre todo, de un gran ori- 


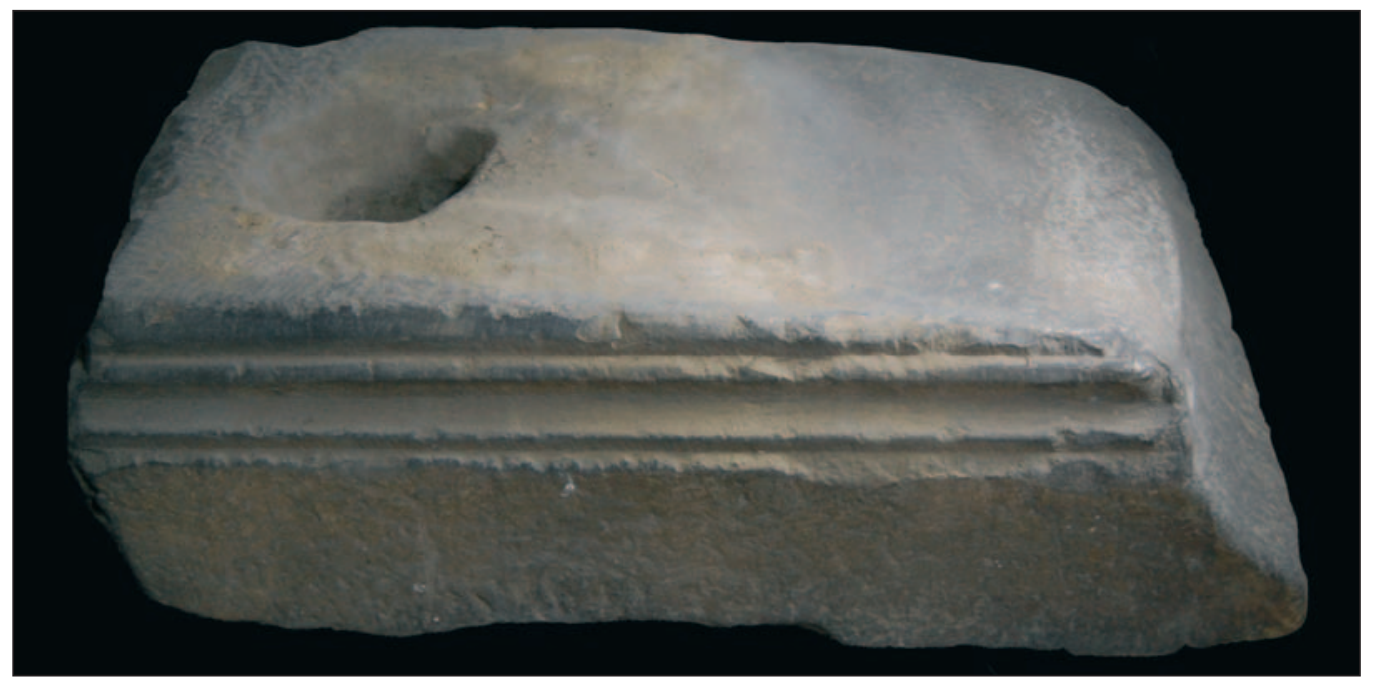

Figura 17. N $^{\circ}$ 43. Dintel o entablamento. Palacio de los Guzmanes (antigua Puerta Cauriense)

ficio circular de $18 \mathrm{~cm}$ de diámetro y 13 de profundidad en una de sus caras sin decorar, nos llevan a plantear que nos encontramos ante la parte superior del quicio de una gran puerta, donde encajaría el espigón que se mueve y gira sobre sí mismo.

El material empleado en este caso se trata de una piedra arenisca muy dura, pesada y resistente, claramente importada.

\section{PROCEDENCIA INDETERMINADA}

En este caso nos encontramos con una nueva pieza procedente de algún lugar de la ciudad de León que forma parte de la colección del Museo desde el siglo XIX.
44.- $\mathrm{N}^{\mathrm{o}}$ inv. 2876. Descontextualizado.

Dimensiones: Long. 90 cm; Anch. 61 cm; Alt. $42 \mathrm{~cm}$.

Friso decorado con guirnaldas realizado en piedra caliza, roto en dos fragmentos y reintegrado antiguamente con cemento (Fig. 18). El campo decorativo está enmarcado por dos listeles longitudinales. Se distingue un motivo central de hoja de acanto, a partir de la cual brotan dos caulículos o roleos, que se dirigen hacia ambos lados retorciéndose en espiral y enmarcando un motivo floral en su interior. Las flores presentan botón central con cinco pétalos redondeados.

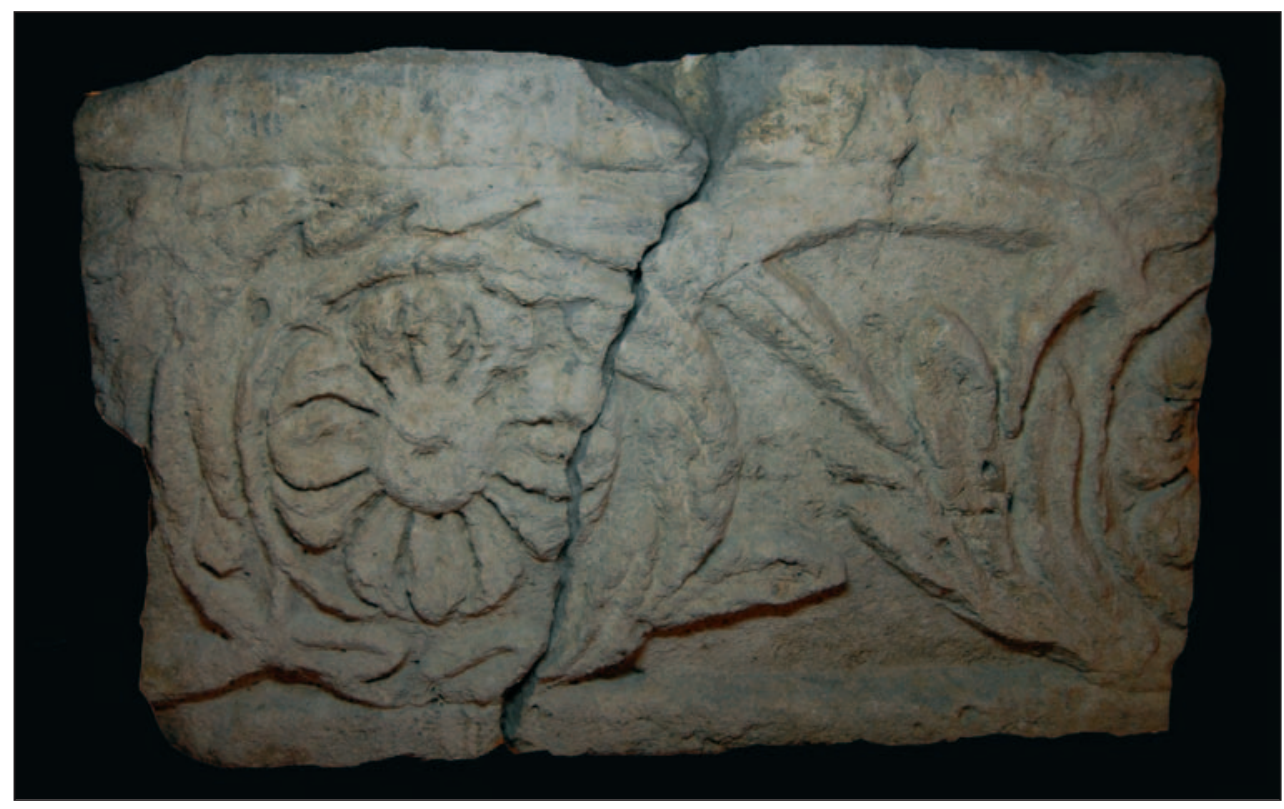

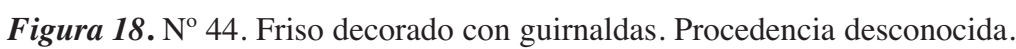




\section{ANÁLISIS ARQUEOLÓGICO DE LOS MATERIALES DECORATIVOS}

Son pocos los elementos de decoración arquitectónica recuperados en la capital leonesa en comparación con los que debieron existir. No obstante, su análisis arqueológico permite contemplar por primera vez un panorama del programa ornamental del León romano, sin lugar a dudas parcial, pero que completa un campo hasta ahora desconocido en la bibliografía científica ${ }^{4}$. Las publicaciones sobre los campamentos de la legio VI victrix y legio VII gemina en León hasta ahora habían soslayado esta cuestión, considerada en principio más propia de grandes urbes que de asentamientos castrenses, caracterizados supuestamente por su sencillez y practicidad. El avance en el conocimiento del León romano nos proporciona una imagen bien distinta, con edificios monumentales, algunos de ellos profusamente decorados (termas, principia), que responden a las mismas tendencias y gustos decorativos propios del mundo urbano, adaptados en este caso a las funciones propias de los acantonamientos militares y en un contexto claramente provincial. Por otra parte, este "vacío" en la arqueología romana de la ciudad de León también responde al intenso reaprovechamiento del que son objeto los elementos arquitectónicos en contextos urbanos actuales, con una larga secuencia ocupacional, agudizados en nuestro caso por la edificación de la muralla a finales del siglo III d. C, que supuso el desmantelamiento de numerosas construcciones tanto interiores como extramuros, cuyos materiales fueron reutilizados en la obra defensiva (García Marcos et alii 2007; Morillo \& Durán, 2008) .

Al igual que sucede en otros yacimientos, uno de los principales problemas que plantea el estudio de muchos restos arquitectónicos radica en su vinculación con diferentes edificios excavados, ya que una buena parte carece de contexto arqueológico claro (p. e. Gutiérrez Behemerid, 2004: 275). En otras ocasiones, aunque ha sido

4 En realidad la ausencia de publicaciones sobre decoración arquitectónica se hace extensible a todo el cuadrante noroeste peninsular. La reciente publicación sobre los marmora de Asturica Augusta (Cisneros et alii, 2010-2011) ha supuesto una gran aportación en la investigación regional.

5 Construcciones como la muralla bajoimperial o la basílica de San Isidoro conservan numerosos elementos arquitectónicos romanos reutilizados (fustes, capiteles, cornisas), que no hemos incluido en este trabajo, cuyo estudio contribuirá posible conocer todos los detalles del registro cronoestratigráfico, no es posible interpretar por el momento el tipo de construcción de la que formaron parte y su ubicación exacta dentro de la misma. A menudo los materiales se encuentran en posición secundaria dentro de las estratigrafías.

Ante la ausencia de contextos arqueológicos cerrados, tan difíciles de hallar en la arqueología urbana, suelen existir numerosos problemas para concretar la cronología de los elementos arquitectónicos, por lo que se suele recurrir a criterios de datación estilísticos, con los elevados márgenes de error que ello implica.

De cualquier forma, y a pesar de las dificultades que acabamos de plantear, inherentes a cualquier estudio de este tipo, la totalidad de los restos que aquí damos a conocer se datan en el periodo comprendido entre el 74 d. C. y los años centrales del siglo III, es decir, al periodo correspondiente a la instalación del campamento de la legio VII gemina (León III) sobre el antiguo campamento de la Legión VI Victrix (León II). La construcción del nuevo campamento legionario supuso una petrificación y monumentalización de las estructuras arquitectónicas anteriores, que fueron parcialmente reaprovechadas. Sin embargo, a diferencia de otras ciudades hispanorromanas, el registro arqueológico y los materiales que damos a conocer en este análisis corroboran que dicha monumentalización no fue acompañada por una marmorización, tal vez por el propio carácter militar del asentamiento o por el simple alejamiento respecto a las fuentes de aprovisionamiento. El mármol se reservó para ciertos usos complementarios, como el revestimiento y la decoración interior de edificios de gran porte.

Un primer análisis de los elementos recuperados revela que se encuentran en estado muy fragmentario, hecho provocado sin duda porque se trata a menudo de piezas rodadas, en especial los revestimientos marmóreos. Es un conjunto muy modesto, bastante homogéneo tanto desde el punto de vista tipológico como del material

en el futuro a completar una visión hasta ahora muy pobre y parcial. El estudio de dichos elementos plantea numerosos problemas. Por una parte los fustes y capiteles romanos reutilizados en diversas iglesias leonesas podrían proceder tanto de la ciudad como de otros lugares, siguiendo una costumbre bien constatada. Por lo que respecta a los materiales reempleados en la obra de la muralla, si bien se encuentran documentados, no es posible medirlos, dibujarlos y analizarlos sin extraerlos de la obra defensiva. 
empleado. Con los escasos elementos de decoración arquitectónica conservados resulta muy difícil llegar a reconstruir el aspecto y los órdenes arquitectónicos de los edificios antiguos de los que formaron parte, por no hablar de la reconstrucción de los estilos decorativos empleados, objetivo último de cualquier estudio de este tipo.

Han llegado hasta nosotros escasos materiales de construcción, sin duda expoliados previamente debido a su mayor facilidad para su reutilización posterior. Dentro de los elementos de sustentación, el conjunto más numeroso está constituido por basas de columnas, de las que se han documentado siete. Las intervenciones del sector de Puerta Obispo han proporcionado una $\left(n^{\circ} 1\right)$; otra procede de la cercana excavación de la plaza de Puerta Obispo $\mathrm{n}^{\circ} 8$ y la calle San Pedro $n^{\circ} 9\left(n^{\circ} 34\right)$; dos se hallaron en la calle Dámaso Merino $\mathrm{n}^{\circ} 6\left(\mathrm{n}^{\mathrm{o}} 35\right.$ y 36$)$; una basa de pilastra cuadrada procede de la calle Santa Marina $\left(\mathrm{n}^{\circ} 37\right)$; de las intervenciones en la calle Conde Luna $\mathrm{n}^{\circ} 9$ se recuperó otra basa in situ $\left(\mathrm{n}^{\circ} 38\right)$; finalmente, fuera de contexto y reutilizada en la fachada de un edificio actual situado en la calle Serradores $n^{\circ} 2$, se encuentra otra más ( ${ }^{\circ} 39$ ).

Mucho mayor interés que su posición en el parcelario actual de la ciudad de León es la asociación directa de las basas aparecidas con edificios de época romana de los que formaron parte (Fig. 19). No cabe duda de que el hallazgo de

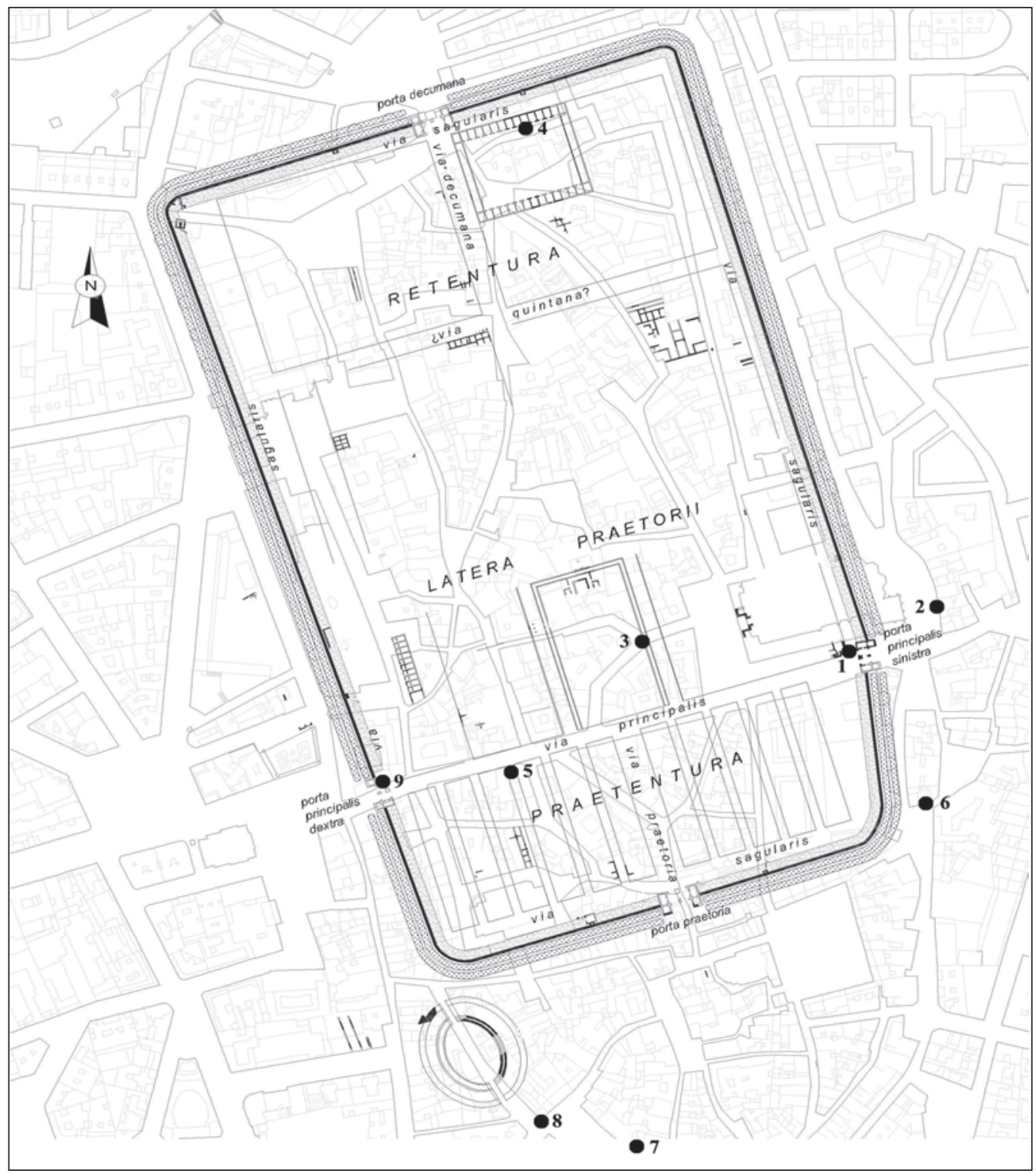

Figura 19. Planta del trazado hipotético del campamento de la legio VII gemina en León, con indicación de los hallazgos mencionados: 1. Puerta Obispo; 2. Plaza de Puerta Obispo ${ }^{\circ} 8 \mathrm{c} / \mathrm{v}$ plaza de San Pedro ${ }^{\circ}$ 9;

3. Dámaso Merino no 6; 4. Calle de Santa Marina; 5. Calle Conde Luna no 9; 6. Serradores $n^{\circ} 2$;

7. Calle Don Gutierre no 4-10; 8. Plaza Don Gutierre; 9. Palacio de los Guzmanes (Puerta Cauriense). 
varios de estos elementos in situ ha facilitado su interpretación. Éste sería el caso de la basa de pilastra cuadrada hallada casi dos metros bajo el pavimento viario de la actual calle Santa Marina $\left(\mathrm{n}^{\circ} 37\right)$, asociada a un suelo altoimperial, cuya posición coincide sin lugar a dudas con la del pórtico septentrional del almacén en torno a patio que ocupa buena parte de la zona nororiental del campamento de la legio VII gemina (Morillo \& García Marcos, 2006: 240; Morillo \& Salido, 2010b: 156-157). Éste sería asimismo el caso de la basa aparecida en la calle Conde Luna ${ }^{\circ} 9\left(n^{\circ} 38\right)$, que parece formar parte del pórtico exterior de un barracón o centuria, también asociado a una calle altoimperial paralela a la vía praetoria del campamento. Por lo que respecta a las dos basas recuperadas en la calle Dámaso Merino $\mathrm{n}^{\circ} 6\left(\mathrm{n}^{\circ} 35 \mathrm{y}\right.$ 36 ), ya en el momento de su descubrimiento se hizo notar que el lugar de aparición coincidía con el espacio que debía ocupar una de las crujías del patio porticado de los principia del campamento legionario (Morillo \& García Marcos, 2006: 252).

Aunque en este caso la certeza sea mucho menor, el hallazgo de dos basas en el sector de Puerta Obispo $\left(\mathrm{n}^{\circ} 1\right.$ y 34$)$ y su cercanía respecto a las antiguas termas romanas, cuyos materiales se encuentran esparcidos por una amplia zona, nos llevan a plantear dicho edificio como su lugar de procedencia.

Respecto a la tipología de las mismas, la mayor parte se trata de basas toscanas muy simples y de pequeño tamaño, cuyo diámetro fluctúa entre 26 y $30 \mathrm{~cm}$. Tan sólo dos de ellas, precisamente las procedentes de la calle Dámaso Merino $\mathrm{n}^{\circ} 6\left(\mathrm{n}^{\mathrm{o}} 35\right.$ y 36$)$ presentan un diámetro de 50-52 cm y una tipología ática. Tanto la elección del orden como la estudiada proporcionalidad no parecen aleatorias y responden sin duda a las necesidades propagandísticas de un edificio más monumental y ornamentado que el resto, como correspondería claramente al cuartel general de la legión.

Por lo que se refiere a los fustes, sólo tres fragmentos han aparecido en intervenciones arqueológicas. Uno de ellos procede de Puerta Obispo, roto en dos fragmentos ( $\left.n^{\circ} 3-4\right)$, también en este caso vinculado posiblemente a las termas legiona-

6 El hecho de que dicho fuste esté tallado en caliza de Espejón, perfectamente constatada dentro del programa ornamental del edificio balneario, es uno de los principales rias'. El otro ingresó en el Museo de León procedente de la calle Don Gutierre $n^{\circ} 4-10\left(n^{\circ} 41\right)$. Se trata de un gran tambor estriado perteneciente a una gran columna o pilastra adosada $\left(n^{\circ} 42\right)$, procedente al parecer del entorno de la plaza de Don Gutierre, que forma parte de las colecciones del Museo de León desde hace años. Tanto por sus dimensiones como por sus características, es una pieza excepcional dentro del conjunto de elementos arquitectónicos recuperados en León, perteneciente sin duda a la fachada monumental de un edificio de gran tamaño. La posición topográfica de este sorprendente hallazgo, coincidente desde el punto de vista espacial con una de las puertas principales del anfiteatro castrense (porta triumphalis) (Durán et alii, 2009: 22-24), podría apuntar posibles pistas sobre su interpretación como parte de la entrada con arco de acceso monumentalizado de dicha construcción.

Por el momento el registro arqueológico de la capital leonesa se muestra sorprendentemente parco en capiteles romanos. Tan sólo ha llegado hasta nosotros un capitel corintio tallado en caliza procedente de la calle Don Gutierre $n^{\circ} 4-10\left(n^{\circ}\right.$ 40), muy alterado y retallado en época posterior.

Otro elemento de decoración arquitectónica que se conserva en los fondos antiguos del Museo de León es parte de un friso decorado con guirnaldas tallado en piedra caliza $\left(n^{\circ} 44\right)$. El esquema compositivo de este friso resulta perfectamente conocido a partir de su creación en época augustea. En Hispania este modelo se constata en ciudades tan alejadas como Tarraco, Barcino, Corduba, Carthago Nova, Uxama y Clunia (cf. Gutiérrez Behemerid, 2003: 196). No es posible precisar su procedencia originaria pero teniendo en cuenta sus grandes dimensiones y su calidad, debió formar parte de un monumento funerario o un gran edificio sobre el que sólo podemos especular.

También descontextualizada se halla una pieza de grandes dimensiones interpretada como parte de un dintel o entablamento, concretamente la parte superior del quicio de una gran puerta $\left(\mathrm{n}^{\circ}\right.$ 43). Nos encontramos ante un elemento tanto funcional como decorativo procedente, según los registros del fondo antiguo del Museo de León,

argumentos a tener en consideración (Morillo \& Salido, 2010: 175-176). 
del palacio de los Guzmanes, lo que indica con toda probabilidad que formó parte del dispositivo de apertura de la antigua porta principalis dextra del campamento romano, coincidente con la Puerta Cauriense medieval. Así lo confirma tanto el tipo de piedra, muy dura y claramente importada, como la presencia de un orificio donde encajaría perfectamente el espigón de la gran quicialera de la puerta.

Finalmente, debemos mencionar la presencia de un fragmento de piedra caliza con decoración figurada indeterminada $\left(n^{\circ} 33\right)$, que pudo haber formado parte de algún programa decorativo de época romana.

Por lo que se refiere a los materiales empleados para la decoración arquitectónica, en su inmensa mayoría se emplea la piedra de origen local, en concreto la caliza ocre o grisácea, mucho más económica. Salvo en algunos casos excepcionales (tal vez $\mathrm{n}^{\circ} 42$ ), la piedra no parece llevar un recubrimiento exterior estucado en blanco, al igual que se constata en otras ciudades interiores como Segobriga (Trunk, 2008: 10). Las evidencias conservadas apuntan a la existencia de una officina lapidaria trabajando para las necesidades de la legio VII gemina, tal vez de carácter temporal. El taller debió desarrollar rasgos estilísticos propios, tomados de otras ciudades vecinas, pero sin duda simplificando los modelos y adaptándolos a las necesidades de un campamento militar, con edificios públicos más funcionales, si bien algunos como las termas o los principia debían mantener cierta monumentalidad acorde con su papel de cara a la representatividad del poder constituido.

Sólo en ocasiones excepcionales se importan materiales lapídeos. Éste sería el caso de la arenisca empleada como dintel de puerta, cuya dureza, necesaria por cuestiones funcionales, la convierte casi en una piedra marmórea; o algunos ejemplares de fustes, basas y otros elementos aislados en piedra de Espejón (Soria), de los que nos ocuparemos algo más adelante cuando hablemos de los marmora foráneos. No debemos descartar el empleo de capiteles y fustes de mármol importado, pero posiblemente fueron los más buscados para reutilizar en edificios posteriores y de ahí que rara vez se hayan conservado en excavaciones actuales. Por el momento, desde el punto de vista arqueológico la presencia del mármol se restringe a los revestimientos interiores, como testimonia la intervención en el sector de Puerta Obispo.
Gran interés reviste el conocimiento de los sistemas de aislamiento de elementos sustentantes (basas) respecto a la humedad del terreno, algo que constituye una necesidad primordial teniendo en cuenta el carácter de la piedra local (caliza fácilmente desmenuzable) y el elevado nivel freático de la capital leonesa ya desde época romana (Morillo, 2008: 10-12). El hallazgo in situ del ejemplar $\mathrm{n}^{\circ} 38$ confirma el empleo de material latericio con dicha finalidad.

Otra cuestión sobre la que merece la pena detenerse es la de la reutilización de los elementos de decoración arquitectónica en momentos posteriores, perfectamente constatada en las estratigrafías leonesas. Tanto en época tardoantigua como en distintos momentos medievales se detecta el reempleo de antiguos elementos sustentantes o decorativos de origen romano como simple material constructivo dentro del concepto de máxima rentabilización de la piedra. Se verifica también el empleo de basas romanas como capiteles dentro de programas decorativos medievales, lo que debió llevar aparejada una imitación de los órdenes romanos originarios para nuevos edificios religiosos.

Puerta Obispo constituye el capítulo más importante y particular de todas las intervenciones arqueológicas realizadas hasta el momento en la ciudad de León en cuanto a decoración arquitectónica se refiere. Este sector ha proporcionado el único conjunto de materiales de revestimiento. Nos encontramos ante piezas talladas en mármol gris veteado en azul o blanquecino, de grano medio o medio-fino, destinadas al revestimiento parietal. Entre ellas destacan las cornisas o remates moldurados $\left(\mathrm{n}^{\circ} 9\right.$ 5-10) y las lastras o placas de revestimiento parietal (crustae) ( $\mathrm{n}^{\circ}$ 11-32). No podemos descartar que alguna crusta corresponda en realidad a losas de pavimento de opus sectile sencillo, de módulos cuadrados, tal y como sucede en otros conjuntos (Rodá, 2001: 113), aunque el grosor de las placas halladas (entre 2 y $4 \mathrm{~cm}$ ) no parece confirmarlo. Dentro de este grupo podría encontrarse asimismo la semicolumna para adosar a la pared $\left(n^{\circ} 2\right)$. El conjunto resulta muy semejante al documentado en la vecina Asturica, que ha proporcionado casi en exclusiva lastras y cornisas molduradas (Cisneros et alii, 2010/11: 115).

De gran interés es el tratamiento de las caras no vistas de las placas, cuyas superficies son rugosas para ser fijadas a la pared mediante argamasa o mortero de cal, tal y como se observa por 
ejemplo en las piezas $n^{0} 7,14,23,30,31,32$. La parte posterior de la basa de la semicolumna $\mathrm{n}^{\circ} 2$ se encuentra rehundida para facilitar su adherencia a la pared. Salvo algunos orificios para introducir pernos de sujeción en las cornisas $\left(\mathrm{n}^{\mathrm{o}} 8,9\right.$ y $10)$ y placas $\left(n^{\circ} 27\right)$, no hay otras huellas de anclaje de las crustae a la pared. Algunos elementos de revestimiento presentan anathyrosis, rehundimientos o resaltes para encajar o fijar otras placas o cornisas contiguas (cornisa ${ }^{\circ} 6$ y lastras 11 y 31 ). En la superficie plana de la pieza 10 se pueden observar las líneas paralelas características del trabajo de talla de la gradina. En la cornisa $\mathrm{n}^{\circ} 7$, se aprecia una posible marca de trabajador en forma de "X", que indica la posición donde ensamblar la placa inferior; en la ${ }^{\circ} 6$ se constata otra en forma de " $H$ " alargada.

El estudio de los materiales decorativos pétreos y los análisis petrológicos de lámina delgada mediante microscopía óptica realizados por la Dra. Isabel Rodà de Llanza, Dr. Aureli Àlvarez Pérez, Dra. Anna Gutiérrez García-Moreno y Dña. Ana Doménech de la Torre de la Unitat d'Estudis Arqueomètrics del ICAC permiten llegar a ciertas conclusiones sobre las canteras de procedencia (ver Apéndice). No se han documentado mármoles importados de fuera de la Península, correspondiendo todos ellos a variantes de marmora hispanos. Tampoco se han identificado calizas marmóreas locales o regionales, como en el vecino asentamiento romano de Astorga, aunque no podemos descartar que nuevos hallazgos confirmen su empleo en la capital leonesa (Cisneros et alii, 2010/11). La gran mayoría de los ejemplares foráneos parecen corresponder a mármoles del anticlinal de Estremoz (Portugal), de grano medio o fino-medio, de los cuales encontramos tanto sus variantes cromáticas blancas como grisáceas veteadas. Los análisis practicados sobre dos piezas representativas de cada una de las variantes ( ${ }^{\circ} 26$ y 27 ) no dejan lugar a duda respecto a su procedencia. Los investigadores responsables proponen un origen en la zona de Borba para la variante blanca grisácea, y de Pardais para la variante veteada. Esta última es muy utilizada para revestimientos parietales como los que aquí presentamos (Àlvarez Pérez et alii, 2009: 65).

Los mármoles de la zona geológica del anticlinal de Estremoz fueron muy explotados en época romana, conociéndose varias zonas que pueden distinguirse por su tonalidad y tamaño del grano (Estremoz, Borba, Pardais, Souzel y Vila Viçosa).
Estas canteras abastecieron a las ciudades de la Lusitania ya desde el periodo augusteo, comenzando por la propia capital, Emerita Augusta, pero también Ebora, Pax Iulia, Conimbriga y Olisipo. También es muy abundante en el ámbito rural (villas de Rabaçal y Milreu). Se ha constatado también su presencia puntual en lugares mucho más alejados, como Baelo Claudia o Carranque (Rodá, 1997: 115; Rodá, 1998: 114115; Rodá, 2001: 112-113; Àlvarez Pérez et alii, 2009: 67; García-Entero \& Vidal, 2008: 596-597). La abundancia de este material en Asturica, ya desde el periodo augusteo-tiberiano (Cisneros et alii, 2010/11: 110-113), y la constatación de su presencia en el campamento de León viene a extender su ámbito de comercialización hacia las regiones interiores septentrionales de Hispania, comprendiendo al menos la mitad sur del conventus Asturum. No podemos obviar el importante papel de la ruta de la Plata en esta conexión, por otra parte perfectamente atestiguada en otros campos de la cultura material como la cerámica (Morillo, 1999: 325) y la moneda (Blázquez Cerrato, 2002). Por el contrario, el mármol de Estremoz se encuentra ausente en otros contextos interiores más orientales como Segobriga (Àlvarez Pérez et alii, 2009, Cebrian, 2012) y Clunia (Gutiérrez Behemerid, 2003), que posiblemente se enmarcan dentro de zonas comerciales diferentes.

También de procedencia hispana es la caliza de Espejón, que se constata en nuestro conjunto. Aparte de un gran labrum (Morillo \& Salido, 2010), se han documentado una basa $\left(n^{\circ} 34\right)$ y dos fragmentos pertenecientes a un mismo fuste de piedra de este tipo ( $\left.n^{\circ} 3-4\right)$. Es un material de color violáceo con vetas amarillentas, que en este caso se disponen de forma transversal, correspondiendo a la variedad "brechada" o mezclada de ambos colores, muy utilizada para elementos estructurales y mobiliario durante la época romana e incluso en los siglos XVI y XVII (Àlvarez Pérez et alii, 2009: 55). Este tipo de marmora procede de las canteras de Espejón, Espeja y Cantalucía, situadas en el límite entre las provincias de Burgos y Soria. Su coloración dota a este tipo de "mármol" de una cualidad ornamental equiparable a mármoles vistosos de importación (García Entero \& Vidal, 2008: 597, fig. 6.6; Àlvarez Pérez et alii, 2009: 54-59).

La caliza de Espejón sería uno más de los "mármoles de sustitución", término sobre la que aún pesan significativas incógnitas (Cisneros, 
2010). El empleo de piedras locales de color era una alternativa económica a la importación, al reducir los gastos de transporte. Este tipo, que recuerda a otros mármoles más conocidos y difundidos en el Imperio, como el "giallo antico" numídico, se empieza a tallar desde época julioclaudia (Mayer, 1992: 18). Se constata su uso para placas de revestimiento, piezas de opus sectile, columnas y como soporte epigráfico (Cisneros, 1988: 61; García Entero \& Vidal, 2008: 597). Su cercanía a Espejón convierte a Clunia en el principal centro de consumo de la piedra de este tipo, donde se emplea tanto para el foro y teatro, como para los revestimientos interiores de los edificios termales (Gutiérrez Behemerid, 2003: 218-219 y 233). Se encuentra en otros ámbitos cercanos a las canteras, como Uxama, e incluso en zonas mucho más alejadas como Caesaraugusta (Cisneros, 2009: e. p.), Carranque (García Entero \& Vidal, 2008: 597), Coca (Segovia) (Àlvarez Pérez et alii, 2009: 59) o Segobriga (Cuenca), yacimiento este último donde alcanza proporciones muy elevadas (Àlvarez Pérez et alii, 2008: 108, Cebrian, 2012:381-383). En el conventus Asturum, además de en León, se ha constatado en notables cantidades en Astorga, en contextos datados en la segunda mitad del siglo I d. C. (Cisneros et alii, 2010/11: 111; cf. Morillo, 2003: 448-449) y en alguna villa de su territorio, como Quintana del Marco (Àlvarez Pérez et alii, 2009: 59).

La elección de las canteras de piedra de Espejón para los programas ornamentales del León romano debió basarse tanto en la calidad estética del material como en la dificultad de hacer llegar material de este tipo a una región alejada de las grandes vías de comunicación marítimo-fluviales, seleccionando tal vez el lugar de aprovisionamiento pétreo más próximo que ofreciera ciertas características de coloración y dureza, empleando alguna de las vías que enlazaban Asturica (Astorga) con Caesaraugusta (Zaragoza).

Desde el punto de vista del aprovisionamiento de rocas ornamentales son muy significativos los paralelismos que presentan Asturica y Legio, a pesar de tratarse uno de un asentamiento urbano y otro de carácter castrense. No cabe duda de que compartieron fuentes de aprovisionamiento (mármoles de Estremoz y calizas de Espejón) y vías de comercialización, a pesar de sus diferencias en cuanto al estatuto jurídico. Las mayores necesida- des de elementos de ornamentación arquitectónica de una ciudad como Asturica Augusta, capital regional y marco de expresión simbólica del Estado romano, dotada de monumentales edificios públicos y lujosas viviendas privadas, determinan que la urbe tuvo que recurrir a marmora locales para sus programas ornamentales, además de materiales lapídeos importados de dentro y fuera de la Península. Tal vez éste sea el motivo de la ausencia de estos últimos en León, si bien podemos encontrarnos tan sólo ante un problema de investigación. Sin descartar una diferencia de comportamiento derivada de la propia jurisdicción militar del campamento de León, que tal vez debe recurrir a canteras situadas a mayor distancia aunque el coste fuera más elevado.

La labra homogénea de las piezas de revestimiento marmóreo de Puerta Obispo revelan la procedencia de un taller local, alguna officina lapidaria situada tal vez en las cercanías de León, posiblemente abierta expresamente para la decoración del edificio del que formaron parte, desaparecida tras su finalización. Los materiales fueron probablemente prefabricados en las mismas canteras de procedencia y transportados hasta el taller final. El paralelismo en cuanto a fuentes de aprovisionamiento tal vez apuntaría un papel destacado de Asturica, donde existieron sin duda talleres lapidarios, en el abastecimiento de marmora decorativos al campamento leonés.

La modestia del conjunto marmóreo de Puerta Obispo que aquí presentamos, donde no aparecen grandes capiteles y cornisas decorativas, se atiene a las pautas de simplicidad propias de los revestimientos interiores de un edificio público de carácter práctico, como se detecta en conjuntos termales (Gutiérrez Behemerid, 2003: 217-219). A juzgar por los elementos recuperados, el espacio o ámbito de los que proceden contaría con un zócalo inferior de lastras de mármol, adornado con medias columnas adosadas y con cornisas molduradas, todo realizado en tonos blancos o grisáceos. Los revestimientos de colores claros son propios de edificios con luz tamizada o reducida, a fin de proporcionar mayor claridad. La parte superior de la pared debería ir pintada también con tonos claros. Asimismo se han recuperado algunos elementos que indican la presencia de algunas columnas exentas y elementos de mobiliario como un gran labrum (Morillo \& Salido Domínguez, 2010). Tanto uno como otras están realizados en caliza de Espejón de tonalidades 
violáceas. Aunque no podemos asegurar con certeza que proceden de los mismos ámbitos, no cabe duda que la combinación de estos elementos con el blanco de los placados marmóreos crearía un efecto de bicromía y claroscuro muy llamativo y característico de algunas decoraciones interiores, lo que nos lleva a apoyar la hipótesis de que formaron parte del mismo programa decorativo de un gran edificio.

Teniendo en cuenta el estatuto de los campamentos, dependientes directamente de la jurisdicción militar, donde no existe lugar para el evergetismo privado, un edificio de estas características sólo puede estar promovido o por el propio legado de la Legión VII o bien por iniciativa de la comandancia imperial, es decir, el emperador, en su calidad de general en jefe de todas las tropas. En este sentido debemos recordar que el futuro emperador Trajano fue legado de la Legión VII en época de Domiciano.

Sobre la identificación de este edificio, los datos anteriores (simplicidad, tipología y material de los revestimientos, presencia de gran labrum) nos llevan a plantear que estamos sin duda ante los restos de la decoración de un ambiente perteneciente a unas grandes termas, edificios prácticos de notables dimensiones y dotados de un programa ornamental de cierta calidad. El lugar de hallazgo de los fragmentos que aquí presentamos apunta en esta misma dirección.

Todos ellos proceden de excavaciones desarrolladas en el espacio comprendido entre la fachada meridional de la catedral de León y el Palacio Episcopal, precisamente donde se alzó la puerta gótica del Obispo. La intervención puso al descubierto los restos de la puerta oriental del campamento de la legio VII gemina, la porta principalis sinistra, obra del periodo flavio-trajaneo realizada en opus quadratum (García Marcos, 2002: 189-195; Morillo \& García Marcos, 2003: 283-286; García Marcos et alii, 2004; Morillo \& García Marcos, 2005). En el transcurso de las excavaciones se documentó asimismo el cierre sureste de las grandes termas romanas existentes bajo la actual Catedral, cuya existencia fue revelada por D. de los Ríos a mediados del siglo XIX (García y Bellido, 1970: 576-577). La habitación excavada estaba ocupada por unas letrinas, cuya construcción aprovechó una estructura precedente, posiblemente una piscina o depósito de agua (García Marcos, 2002: 201). Flanqueando las termas discurría una calle romana repavimentada en diversas ocasiones.
Los elementos arquitectónicos aquí presentados aparecieron fuera de su contexto original, claramente desplazados y en posición secundaria, en niveles de relleno y aterrazamiento datados entre mediados del siglo III d. C. y el periodo altomedieval (siglos X-XI). Siempre aparecen acompañados por restos constructivos de diverso tipo (fragmentos de mosaico y opus signinum, tubuli latericii, tégulas, ladrillos de opus spicatum, restos de decoración pictórica, etc.). Su tipología y paralelos, así como su posición topográfica y el momento de amortización, permiten avanzar hipótesis sobre su procedencia originaria y contextualización dentro de las arquitecturas que los contuvieron, así como establecer su evolución posterior. Más que a la puerta del campamento, de arquitectura mucho más funcional, las piezas corresponden con casi total seguridad a la decoración interior del vecino edificio de las termas legionarias, construidas posiblemente entre el período flavio y los años iniciales del siglo II d.C. (Morillo \& García Marcos, 2003: 284-286, nota 57; García Marcos et alii, 2004).

En ningún caso se documentaron piezas in situ. La mayor parte procede de estratos datados en época bajoimperial, asociados a superficies de paso o trabajo (UE 1104, 1116, 1119, 4026, 4042 y 4048), entre las que destacan la reforma en el suelo del cuerpo de guardia de la torre septentrional de la puerta (UE 1028B), el desmantelamiento de estructuras altoimperiales (UE 1035), y el subsector situado entre las termas y la muralla con grandes vertidos de opus signinum mezclados con restos marmóreos (UE 4021). El conjunto más significativo, donde se encuentran además las piezas de mayor calidad y mejor conservadas (cornisas, semicolumna, fragmentos de lastras de mayores dimensiones), acompañadas de abundante material constructivo, se encontró en el relleno del canal exterior de las letrinas de las termas (UE 5012). La amortización intencionada de este canal, ligada a profundas reformas en el interior del edificio termal, que supusieron la transformación de estancias enteras, se produjo en algún momento bajoimperial. Los hallazgos numismáticos fechan el abandono de las letrinas de las termas a mediados del siglo III d. C. (Morillo \& Gómez Barreiro, 2006: 189-191), momento que puede corresponder a la gran renovación del complejo balneario. 
También se detectan puntualmente fragmentos marmóreos decorativos en horizontes tardoantiguos (UE 1035, 4010 y 4011), por lo general bastante rodados. El resto de piezas formaban parte de estratos muy posteriores: rellenos de hoyos medievales (UE 1090 y 4040) y trincheras de cimentación de muros de época moderna o contemporánea (UE 1020 y 1026); incluso formaban parte de muros medievales (UE 1147 y 4019). Todos ellos pueden corresponder a la destrucción definitiva de las termas romanas y la creación de una gran plataforma para construir la catedral románica, lo que supuso una gran remoción de tierras y diversos materiales de acarreo y la transformación de la topografía de toda la zona, además de la reutilización como material constructivo de antiguos marmora. Algunos elementos fueron reutilizados en la obra religiosa medieval, como la basa $n^{\circ} 1$.

En definitiva, hemos tratado de aproximarnos en este estudio a los programas arquitectónicos y ornamentales del antiguo campamento de la legio VII gemina en León a través de los elementos sustentantes o decorativos que se van documentando. El panorama dista mucho de la simplicidad constructiva que se consideraba característica inherente a cualquier establecimiento militar. Es preciso contemplar de una manera diferente dichos asentamientos, donde su carácter eminentemente práctico no tiene por qué entrar en contradicción con una monumentalidad acorde con las características del poder encarnado por el ejército romano, una expresión más del propio emperador, en definitiva comandante en jefe de todas las fuerzas militares.

\section{BIBLIOGRAFÍA}

Àlvarez Pérez, A., Cebrián, R. \& RodÁ, I. (2008): "El mármol de Almadén de la Plata y los marmora importados del foro de Segóbriga", T. Nogales Barrasate \& J. Beltrán (eds.): Marmora Hispana: Explotación y uso de los materiales pétreos en la Hispania romana, Colección Hispania Antigua, Serie Arqueológica 2, Roma, 101-120.

Àlvarez Pérez, A., Domènech De la Torre, A., Lapuente Mercadal, P., Pitarch Martí, À. \& Royo Plumed, H. (2009): Marbles and stones of Hispania. Exhibition Catalogue, Tarragona.

Blázquez Cerrato, C. (2002): Circulación monetaria en el área occidental de la Península Ibérica. La moneda en torno al camino de la Plata, Archéologie et Histoire Romaine 6, Montagnac.
Cebrian, R. (2012): "Mármoles coloreados de producción hispana utilizados en la decoración arquitectónica de edificios públicos en Segobriga (Saelices, Cuenca)", G. Carrasco Serrano (coord), La ciudad romana en Castilla - La Mancha, Cuenca, 371-396.

Cisneros Cunchillos, M. (1988): Mármoles hispanos su empleo en la España romana, Monografías Arqueológicas 29, Zaragoza.

Cisneros Cunchillos, M. (1997): “Mármoles de importación y mármoles de sustitución: su utilización en algunas ciudades hispanas", Veleia 14, 199-204.

Cisneros Cunchillos, M. (2009): "El uso del marmor en el valle del Ebro", I Coloquio de Arqueología en Carranque: Marmora romanos en Hispania, Carranque (en prensa).

Cisneros Cunchillos, M. (2010): "Reflexiones sobre los mármoles hispanos: revisando la expresión "mármoles de sustitución", Marmora 6, 1351150 .

Cisneros Cunchillos, M., Gisbert-Aguilar, J. \& Somovilla DE Miguel, I. A. (2010/11): "El uso del mármol en la arquitectura de Asturica Augusta", Anales de Arqueología Cordobesa 2122, 93-126.

Durán, R., Fernández OchoA, C. \& Morillo, A. (2009): "The Amphitheatres in Hispania: recent investigations", T. Willmott (ed.), Roman Amphitheatres and Spectacula: a 21 $1^{\text {st-Century }}$ Perspective, BAR Int. Series 1946, Oxford, 1528.

Fusco, A. \& Mañas Romero, I. (2006): Mármoles de Lusitania, Mérida.

García Entero, V. \& Vidal, S. (2008): "Los marmora y la decoración arquitectónica del edificio A de Carranque (Toledo): Primeros resultados", C. Fernández Ochoa, V. García Entero \& F. Gil Sendino (coord.): Las villae tardorromanas en el occidente del imperio: Arquitectura y Función. Gijón, 588-605.

GARcía Marcos, V. (2002): "Novedades acerca de los campamentos romanos de León", A. Morillo (coord.), Arqueología Militar Romana en Hispania, Anejos de Gladius 5, Madrid, 167-212.

García Marcos, V., Campomanes, E. \& Miguel HeRnÁNDEZ, F. (2004): "El solar y el entorno urbano de Santa María de Regla (ss. I-XV)", J. Yarza, M ${ }^{\mathrm{a}}$ V. Herraez \& G. Boto (eds.), Congreso Internacional: La Catedral de León en la Edad Media, León, 23-44. 
Garcia Marcos, V., Durán, R. \& Morillo, A. (2007): "La muralla tetrárquica de Legio: aproximación al conocimiento de su sistema constructivo", A. Rodríguez Colmenero \& Rodá, I. (eds.), Murallas de Ciudades Romanas en el Occidente del Imperio, Lugo, 381-399.

GARcíA y BELlido, A. (1970): "Estudios sobre la Legio VII Gemina y su campamento en León", Legio VII Gemina, León, 569-599.

GutiÉRREZ BEHEMERID, M. A. (2003): La decoración arquitectónica en la Colonia Clunia Sulpicia, Studia Archaeologica 92, Valladolid.

GuTIÉRREZ BEHEMERID, M. A. (2004): “Los programas arquitectónicos de época imperial en el conventus Cluniensis", S. F. Ramallo Asensio (ed.), La decoración arquitectónica en las ciudades romanas del Occidente, Murcia, 275-292.

MÁrquez, C. (1998): La decoración arquitectónica de Colonia Patricia. Una aproximación a la arquitectura y urbanismo de la Córdoba romana, Córdoba.

MAYER, M. (1992): 'L'exploitation des ressources lapidaires en Hispanie", Les Dossiers d'Archeologie 173, 16-21.

MAYeR, M. (2008): “A propósito de las canteras de Vila Viçosa, Estremoz y CIL II, 133”, $O$ Arqueólogo Português 26, 407-414.

Morillo, A. (1999): Lucernas romanas en la región septentrional de la Península Ibérica. Contribución al conocimiento de la implantación romana en Hispania, Monographies Instrumentum 8, Montagnac

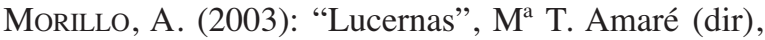
Astorga IV: lucernas y ánforas, León, 10-622.

Morillo, A. (2008): "Cultos militares y espacios sagrados en el campamento de la legio VII gemina en León”, Gerión 26, 2008, 379-405.

Morillo, A. (2010): "De Castra Legionis a Leione: León desde sus orígenes al siglo VIII", M. Torres Sevilla (ed.), Congreso Internacional Regnum Legionis (910-1230), León, en prensa.

Morillo, A. \& Durán, R. (2008): “Caracterización tipológica de la muralla de León: resultados preliminares de la lectura de paramentos", IV Congreso de Obras Públicas en la Ciudad Romana, Lugo-Guitiriz, 77-94.

Morillo, A. \& García Marcos, V. (2003): “Legio VII Gemina and its Flavian fortress at León”, JRA 16, 275-286.
Morillo, A. \& García Marcos, V. (2005): “The defensive system of the legionary fortress of VII gemina at León (Spain). The porta principalis sinistra", Z. Visy (ed.), Limes XIX. Proceedings of the XIXth International Congress of Roman Frontier Studies (2003), Pécs, 569-583.

Morillo, A. \& García Marcos, V. (2006): "Legio (León). Introducción histórica y arqueológica", $\mathrm{M}^{\mathrm{a}}$ P. García-Bellido (coord.), Los campamentos romanos en Hispania (27 a. C.-192 d. C.). El abastecimiento de moneda, Anejos de Gladius 9, Madrid, 225-243.

Morillo, A. \& García Marcos, V. (2006): "Cronologías estratigráficas: cerámica y moneda", M ${ }^{\mathrm{a}}$ P. García-Bellido (coord.), Los campamentos romanos en Hispania (27 a. C.-192 d. C.). El abastecimiento de moneda, Anejos de Gladius 9, Madrid, 244-257.

Morillo, A. \& Gómez Barreiro, M. (2006): "Circulación monetaria en los campamentos romanos de León”, M M P. García-Bellido (coord.), Los campamentos romanos en Hispania (27 a. C.192 d. C.). El abastecimiento de moneda, Anejos de Gladius 9, Madrid, 258-303.

Morillo, A. \& SAlido Domínguez, J. (2010): "Labrum procedente de las termas del campamento de la legio VII gemina en León”, Zephyrus LXV, 167-178.

Morillo, A. \& SAlido Domínguez, J. (2010b): “El aprovisionamiento del ejército romano en Hispania. Transporte, almacenaje y redistribución”, J. J. Palao Vicente (ed.), Militares y Civiles en la antigua Roma. Dos mundos diferentes, dos mundos unidos, Salamanca, 135-164.

Muñoz Ojeda, F. J. \& SARabia Bautista. J. (2000): "Aportación a los estudios sobre el uso de mármoles locales en el sureste peninsular. La Alcudia de Elche (Alicante)", Anales de Prehistoria y Arqueología Universidad de Murcia 16, 169-185.

Pensabene, P. (1997): “Amministrazione dei marmi e sistema distributivo nel mondo romano", G. Borghini (ed.), Marmi Antichi, Roma, 43-54.

PEÑA JURADO, A. (2009): "La decoración arquitectónica", R. Ayerbe, T. Barrientos F. Palma (eds.), El Foro de Augusta Emerita. Génesis y evolución de sus recintos monumentales, Anejos Archivo Español Arqueología LIII, Mérida, 525-582.

Ramallo Asensio, S. F. (ed.) (2004): La decoración arquitectónica en las ciudades romanas del Occidente, Murcia.

RodÁ, I. (1997): "Los mármoles romanos de Hispania”, Histria Antiqua 4, 47-56 
RoDÁ, I. (1998): "La explotación de las canteras en Hispania", VV.AA., Hispania: el legado de Roma en el año de Trajano (Zaragoza), 113-118.

RodÁ, I. (2001): "Los mármoles de Carranque", Carranque, centro de Hispania romana, Alcalá de Henares, 111-118.

RodÁ, I. (2004): "Uso y comercio del mármol”, Histria Antiqua 12, 39-44.

RodÁ, I. (2007): "El metal y el agua”, Sautuola XIII (C. Fernández Ibáñez (ed.), Metalistería en la Hispania romana), 301-320.

RodÁ, I. (2009): “Marmora en Hispania: marmora importados e hispanos", I Coloquio de Arqueología en Carranque. Marmora romanos en Hispania, Carranque, en prensa.

SOler Huertas B. (2008): "Marmora de importación y materiales pétreos de origen local en Hispania: explotación, comercio y función durante los periodos tardorrepublicano e imperial", J. Uroz, J. M. Noguera, F. Coarelli (eds.), Iberia e Italia. Modelos romanos de integración territorial, Murcia, 711-732.

Torreras Palacios, S. (2009): "Un vertedero de material arquitectónico romano en el antiguo cuartel de S. Rafael (Córdoba)", Anales de Arqueología Cordobesa 20, 461-482.

TRunK, M. (2008): Los capiteles del foro de Segobriga. Evaluación tipológica y estilística, Cuenca.

VAQUERIZO, D. (1990): "La decoración escultórica de la villa romana de "El Ruedo" (Almedinilla, Córdoba)", Anales de Arqueología Cordobesa 1, $125-154$

VAquerizo D. \& Noguera CeldRÁn, J. M. (1997): La villa romana de El Ruedo (Almedinilla, Córdoba): decoración escultórica e interpretación, Córdoba.

\section{APÉNDICE: INFORME DEL ANÁLISIS DE 3 MUESTRAS DE MAR- MORA PROCEDENTES DE LAS TER- MAS LEGIONARIAS DE LEÓN}

Dra. Isabel Rodà de Llanza

Dr. Aureli Àlvarez Pérez

Dra. Anna Gutiérrez Garcia-Moreno

Dña. Ana Doménech de la Torre

ICAC

\section{INTRODUCCIÓN}

Por encargo del arqueólogo profesor Ángel Morillo (Universidad Complutense de Madrid) se han realizado los análisis mediante microscopia óptica de tres muestras de marmora procedentes de las termas legionarias de León, con el objetivo de identificar el tipo de material y su lugar de origen. Las muestras se encontraron deslocalizadas dentro del yacimiento debido a la destrucción que han sufrido las termas y junto con restos de signinum, algunas teselas, pinturas parietales, etc.

\section{Datos del conjunto}

Yacimiento / procedencia: termas legionarias de León

Cronología: termas construidas al final del siglo I o principios del II.

Campaña de excavación: 2004

Muestras analizadas: 3

\begin{tabular}{|l|l|l|l|l}
\hline Código & Tipo de & Num. Inventario & Procedencia/U & Observaciones
\end{tabular}

muestra material pieza de origen $\mathrm{E}$

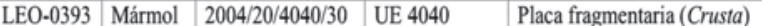

\begin{tabular}{|l|l|l|l|l|l}
\hline LEO-0394 & Mármol & 2004/20/4026/23 & UE 4026 & Placa fragmentaria (Crusta)
\end{tabular}

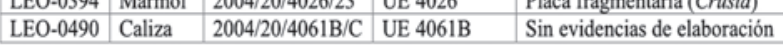

Tipo de análisis: análisis mediante microscopia óptica de polarización.

Metodología: las láminas delgadas para su posterior observación microscópica, han sido realizadas en el Laboratorio de Preparación de Láminas Delgadas del Departamento de Geología de la Universidad Autónoma de Barcelona (UAB); las observaciones en el microscopio óptico de polarización, correspondientes fotografías y comparación con muestras de referencia de los principales tipos de mármoles utilizados en época romana, han sido llevadas a cabo en la Unidad de Estudios Arqueométricos del Institut Català d'Arqueologia Clàssica (ICAC). Para ello se han utilizado los materiales de referencia depositados en el Laboratorio para el Estudio de Materiales Lapídeos en la Antigüedad (LEMLA), de la UAB, y otras muestras depositadas en el ICAC.

Equipo: para llevar a cabo las observaciones y las descripciones microscópicas se ha utilizado un microscopio de luz polarizada NIKON Eclipse 50iPOL, a 20x, 40x y 100x. Para realizar las fotografías se ha utilizado una cámara NIKON COOLPIX5400 acoplada al microscopio mediante un adaptador NIKON COOLPIX MDC Lens.

\section{RESULTADOS:}

\section{1.- Muestra de la pieza $n^{0} 27$ ( No: $^{\circ}$ LEO-0393).}

\section{Descripción macroscópica:}

Mármol de grano fino y de color blanco grisáceo que presenta un bandeado de color gris más oscuro. 


\section{Descripción microscópica:}

Mármol de grano fino medio y heterogranular no seriado. Los granos son idiomórficos, bien recristalizados y presentan abundancia de puntos triples. Presenta un pequeño bandeado por toda la lámina. La textura es granoblástica. La lámina tiene pequeñas fracturas recristalizadas con calcita.

\section{Minerales:}

- Calcita: de tamaño de grano fino- medio, presenta maclas muy abundantes y deformadas.

- Clorita: de tamaño fino- medio, se presenta en forma de láminas de contorno poligonal. Tiene una ligera tonalidad azulada en nicoles paralelos

- Feldespatos: cristales muy pequeños, difíciles de localizar, y en poca cantidad.

- Cuarzo: cristales muy pequeños, difíciles de localizar, y en poca cantidad.

- Minerales opacos: minerales de hierro muy posiblemente.

\section{Interpretación:}

Se trata de un mármol portugués, posiblemente procedente de la zona de Borba, donde aparecen niveles de mármoles de grano fino como resultado de restos del metamorfismo regional. Apenas está afectado por las intrusiones que originaron el metamorfismo de contacto y que dieron como resultado los mármoles de grano grueso más típicos del anticlinal de Estremoz (Portugal). La comparación de la muestra con láminas de referencia de materiales procedentes de las canteras del anticlinal de Estremoz (concretamente con la muestra EST-10.212), nos presenta aspectos coincidentes que apuntan en esta dirección.

\section{2.- Muestra de la pieza $n^{0} 26$ ( $\mathbf{N}^{\circ}$ : LEO-0394)}

\section{Descripción macroscópica:}

Mármol de color gris con vetas de color azulado y de grano fino. El bandeado es más acusado que en la muestra anterior (LEO-393).

\section{Descripción microscópica:}

Mármol de grano fino, bien cristalizado, con numerosos puntos triples. Las maclas de la calcita están ligeramente deformadas y los granos presentan una orientación en toda la lámina. La muestra presenta bandas que se distinguen entre sí por el diferente tamaño de grano. Las láminas de clorita se disponen paralelamente a la orientación general. Presencia de algunos minerales opacos.

\section{Minerales:}

- Calcita: de tamaño fino- medio. Se presenta en un bandeado de diferentes tamaños de grano y presenta las maclas polisintéticas ligeramente deformadas.

- Plagioclasas: cristales muy pequeños, difíciles de visualizar, y en muy pequeña cantidad.

- Feldespatos: cristales muy pequeños, difíciles de localizar, y en muy pequeña cantidad.

- Clorita: presenta, de forma localizada, forma de agregados fibrosos, pero generalmente, está en forma de cristales poligonales. De tamaño de grano fino medio, presenta una tonalidad azulada en nicoles paralelos.

- Cuarzo: cristales muy pequeños, difíciles de localizar, y en muy pequeña cantidad.

- Circón: pequeños cristales en forma de prismas alargados y acabados en forma de triángulo. Poco abundantes.

\section{Interpretación:}

El material de esta muestra presenta concomitancia con la anterior (LEO-0393) especialmente en lo que respecta a orientación y forma de los granos, aunque en este caso de menor tamaño. Se trata de un mármol de grano fino, bien cristalizado, y con los granos de la matriz orientados. La comparación de la muestra con láminas de referencia de materiales procedentes de las canteras del anticlinal de Estremoz (concretamente, EST10.215, EST-10.218 y EST-10.223), nos presenta aspectos coincidentes entre las muestras.

\section{3.- Muestra de la pieza $\mathrm{N}^{0}$ : LEO-0488}

\section{Descripción macroscópica:}

Caliza de color ocre y con porosidad abundante.

\section{Descripción microscópica:}

La muestra analizada es una caliza biomicrítica con vetas de recristalización. La matriz micrítica tiene una porosidad muy abundante. Esta porosidad es móldica, así que, no sin ciertas dificultades, se pueden distinguir los lugares que estaban ocupados por fragmentos de bioclastos, seguramente de bivalvos y equinidos. La calcita de recristalización es de tamaño medio grueso, heterogranular y con las aristas de los cristales rectilí- 
neas. La diferencia de tamaños podría deberse a las diferentes etapas en la cristalización de la fractura. No se observan otros minerales.

\section{Interpretación:}

El material es de procedencia local aunque el momento de su sedimentación corresponde a una zona de costa. Corrobora esta teoría la presencia de fósiles marinos muy fragmentados. El ambiente de sedimentación fue muy tranquilo, porque no se observan indicios de movimiento de material, y con resedimentaciones de calcita. Se trata de una caliza local de edad geológica indeterminada.

\section{CONCLUSIONES}

A partir del aspecto macroscópico y microscópico del conjunto de muestras analizado, se han identificado dos tipos de roca diferentes, dos mármoles y una caliza.

A modo de conclusiones podemos destacar los siguientes aspectos:

- Las dos muestras de mármol (LEO-0393 y LEO-0394) han sido comparadas con los principales tipos de marmora utilizados en la antigüedad y se descarta totalmente un origen nohispánico del material. La procedencia de las muestras ha sido cotejada con diferentes materiales de similares características, siendo descartados los mármoles de la zona de SaintBéat (Pirineos) y los de la zona de Incio (Lugo). Los materiales de Saint Béat presentan características muy diferentes a los estudiados, siendo de tamaño y forma de grano diferente, abundancia de maclas finas deformadas y con presencia de granos de menor tamaño alrededor de los cristales más grandes. A modo de hipótesis, la observación macroscópica hizo pensar en que podía tratarse de un mármol procedente de Incio (Lugo). Sin embargo, a nivel microscópico, las muestras presentan unos rasgos diferentes a los de la zona gallega, en especial el tamaño y forma de los cristales y la poca presencia de micas en las muestras.

- Los materiales de la zona de Borba, en el anticlinal de Estremoz (Portugal), son los que presentan las características más similares a los analizados. En el caso de la muestra LEO0394, podría proceder en concreto de Pardais.

- La muestra de caliza (LEO-488) es una biomicrita con señales de recristalización. Presenta una porosidad móldica bastante abundante y restos de bioclastos, posiblemente foraminíferos, imposibles de identificar y por lo tanto, no se ha podido determinar la edad geológica de la muestra. Estamos delante de una caliza de origen local de procedencia cercana a León pero que para poder precisar el afloramiento concreto se debería hacer un estudio de campo más detallado de los materiales de la zona.

\section{BibliografiA}

DunHAM, R. J. (1962): “Classification of carbonates rocks according to depositional textures", W. E. Ham (ed.), Classification of carbonate rock. Am. Assoc. Petrol. Geol. Mem. 1, 108-121.

FOLK, R. L. (1959): "Practical petrographic classification of limestones", Bull. Am. Assoc. Petrol. Geol. 40, 1-38.

FOLK, R. L. (1962): "Spectral subdivision of limestones types", W. E. Ham (ed.), Classification of carbonate rocks. Am. Assoc. Petrol. Geol. Mem. $1,62-84$. 
